\title{
Integrated transcriptomics and metabolomics decipher differences in the resistance of pedunculate oak to the herbivore Tortrix viridana $\mathrm{L}$.
}

Birgit Kersten ${ }^{1}$, Andrea Ghirardo², Jörg-Peter Schnitzler², Basem Kanawati ${ }^{3}$, Philippe Schmitt-Kopplin ${ }^{3}$, Matthias Fladung ${ }^{1}$ and Hilke Schroeder ${ }^{1 *}$

\begin{abstract}
Background: The interaction between insect pests and their host plants is a never-ending race of evolutionary adaption. Plants have developed an armament against insect herbivore attacks, and attackers continuously learn how to address it. Using a combined transcriptomic and metabolomic approach, we investigated the molecular and biochemical differences between Quercus robur L. trees that resisted (defined as resistant oak type) or were susceptible (defined as susceptible oak type) to infestation by the major oak pest, Tortrix viridana $\mathrm{L}$.

Results: Next generation RNA sequencing revealed hundreds of genes that exhibited constitutive and/or inducible differential expression in the resistant oak compared to the susceptible oak. Distinct differences were found in the transcript levels and the metabolic content with regard to tannins, flavonoids, and terpenoids, which are compounds involved in the defence against insect pests. The results of our transcriptomic and metabolomic analyses are in agreement with those of a previous study in which we showed that female moths prefer susceptible oaks due to their specific profile of herbivore-induced volatiles. These data therefore define two oak genotypes that clearly differ on the transcriptomic and metabolomic levels, as reflected by their specific defensive compound profiles.

Conclusions: We conclude that the resistant oak type seem to prefer a strategy of constitutive defence responses in contrast to more induced defence responses of the susceptible oaks triggered by feeding. These results pave the way for the development of biomarkers for an early determination of potentially green oak leaf roller-resistant genotypes in natural pedunculate oak populations in Europe.
\end{abstract}

Keywords: RNA sequencing, Transcriptomics, Metabolomics, Defence response, Quercus robur, Tortrix viridana

\section{Background}

Plants suffer constantly from herbivore pressure, and their defence responses are therefore highly evolved and tightly regulated. With more than 200,000 secondary metabolites, plants directly resist microbial and insect attacks, animal predation [1,2], and multiple environmental stresses $[3,4]$. The suite of secondary metabolites in plants is composed both of metabolites that are consti-

\footnotetext{
*Correspondence: hilke.schroeder@ti.bund.de

${ }^{1}$ Thünen Institute of Forest Genetics, Sieker Landstrasse 2, D-22927, Grosshansdorf, Germany

Full list of author information is available at the end of the article
}

tutively expressed in different plant tissues and of inducible compounds that complete the overall armament of plants in response to herbivore feeding $[5,6]$.

To ensure optimal defence responses, plants must be able to up- and down-regulate primary and secondary metabolic pathways at every level to exert temporal and spatial control in an effective and efficient way, thereby minimising damage and ensuring vegetative growth and reproduction [7]. For this purpose, plants have evolved constitutive and induced defence mechanisms. Preformed molecular [8], chemical, and physical mechanisms may reduce the accessibility or availability of the

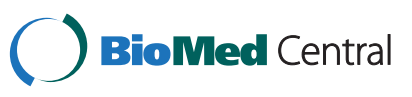


plant resources to herbivorous insects. For example, one of the most important groups of constitutive defence compounds that act against herbivores and pathogens are the condensed tannins (proanthocyanidins; PA) [7,9]. These are polyphenolic compounds synthesised via the flavonoid biosynthetic pathway. Analyses of specific PAs have been performed in many tree species, such as poplar and oaks (e.g., $[10,11])$ and in herbaceous plants (e.g., [9]). In oak foliage, for example, different levels of condensed tannin content in combination with nitrogen content seem to be essential in determining the susceptibility to herbivorous insects [12,13]. In addition to the condensed tannins, the so-called hydrolysable tannins (i.e., gallotannins, ellagitannins) are also important and have only recently become a focus of research into the defence response [14]. Interestingly, insect specialists prefer lower tannin content than do insect generalists [9].

Inducible defence reactions involve a broad range of molecules whose synthesis is temporally controlled [7]. We know of at least two types of inducible defence responses: the direct defences that inhibit the growth or development of herbivorous insects and the indirect defences that include the plant volatiles, which may, for example, attract the parasitoids and predators of the herbivore $[15,16]$.

Transcript profiling using DNA microarrays has significantly improved our understanding of the regulatory and transcriptional networks of gene activation/inactivation in plants during plant-insect interaction [17-19]. However, while this technology is restricted to profiling transcripts that are represented by corresponding DNA probes on the microarray, recent developments in RNA sequencing (RNAseq) allow the genome-wide profiling and quantification of transcripts, and these approaches can be used to study plant defence responses in more comprehensive detail [20-22]. To date, the use of RNAseq in studies of herbivory has been rare. Gilardoni et al. [23] analysed the Nicotiana attenuata transcriptome using SuperSAGE and 454 sequencing after elicitation with fatty acid-amino acid conjugates known to act as elicitors in Manduca sexta herbivory.

As transient or constitutive end products of the cascade that begins with gene activation, the constituents of the metabolome define the biochemical phenotype of an organism. Thus, quantitative and qualitative measurements of the plant metabolome during herbivory can provide a wide overview of the biochemical status of the plant and essential information regarding the influence of metabolite levels on the phenotype [24].

In the present work, we applied RNAseq and nontargeted metabolome analysis, performed using Fourier Transform Ion Cyclotron Mass Spectrometry (FT-ICR-MS) [25], to examine the transcriptional and metabolomic differences in pedunculate oak (Quercus robur L.) varieties that differ in their degree of defoliation and susceptibility to herbivory by the green oak leaf roller (Tortrix viridana L., Lepidoptera: Tortricidae). T. viridana is a specialist herbivorous insect that feeds only on species of the genus Quercus [26,27]. In Central Europe, the perpetual outbreak of the green oak leaf roller is one reason for oak decline events reported during the last century. During a past outbreak episode in Germany in the years 2003-2005, in which T. viridana caused almost the complete defoliation of oaks in a selected forest stand in North Rhine-Westphalia, we observed that a few individual oaks were remarkably less defoliated than neighbouring trees. We defined these lessdefoliated individuals as resistant ('T-oaks') and the heavily defoliated trees as susceptible ('S-oaks') [28]. In recent work, we demonstrated that the resistance of T-oaks to herbivore attack by $T$. viridana is related to the amount and scent of herbivory-induced plant volatiles (HIPVs). In the same study, we showed that the $\mathrm{T}$ - and $\mathrm{S}$-oaks differed in their polyphenolic leaf constituents [29].

To unravel the underlying molecular mechanisms related to the resistance and susceptibility of oaks towards herbivory by $T$. viridana, we performed controlled laboratory experiments to identify candidate genes that exhibited induced differences in their expression patterns after insects feeding. Moreover, analysing the unfed control plants aided in the identification of candidate genes that exhibit constitutive expression differences between the oak types. To complete our systems biological approach, we comparatively analysed the metabolome of $\mathrm{T}$ - and S-oaks to correlate gene expression patterns and metabolite profiles. Moreover, this analysis provided the opportunity to identify the overall metabolomic differences between $\mathrm{T}$ - and $\mathrm{S}$-oaks in addition to the local and systemic changes induced by $T$. viridana feeding or by developmental alterations in plant metabolite patterns.

\section{Results}

Transcriptional differences between T- and S-oaks after $T$. viridana feeding

As a first step, we used the MapMan tool [30] for displaying the transcriptional differences between $\mathrm{T}$ - and S-oaks after $16 \mathrm{~h}$ of $T$. viridana feeding to obtain a global overview of the related cellular pathways. All transcripts showing any difference in their expression level (RPKM-value: reads per kilobase of exon model per Million mapped reads) between the $\mathrm{T}$ - and $\mathrm{S}$-oaks after $T$. viridana feeding were included in this analysis. When comparing the two oak types, 30 MapMan functional categories (BINs) showed a significantly different average BIN response ( $\mathrm{p}<0.05$, Wilcoxon rank sum test in the MapMan tool; Additional file 1) compared to the response of all other BINs. The most significant of these BINs are related to 
photosynthesis and ribosomal protein synthesis, while other differences were identified in BINs related to chromatin structure, redox, targeting to mitochondria, and other cellular functions (Additional file 2).

In the second step, we selected candidate transcripts that were potentially involved in the different transcriptional responses of $\mathrm{T}$ - and $\mathrm{S}$-oaks to $T$. viridana feeding. In total, we found 858 transcripts that were differentially expressed in response to $T$. viridana feeding. Of these, 389 had higher expression values in T-oaks than in S-oaks ( $\mathrm{T}_{\mathrm{FED}}>\mathrm{S}_{\mathrm{FED}}$-group; log2 fold change $\geq 1.5$ ), while 469 had lower expression values $\left(\mathrm{T}_{\mathrm{FED}}<\mathrm{S}_{\mathrm{FED}}\right.$-group; $\log 2$ fold change $\leq-1.5$; Additional file 3 ). Figure $1 \mathrm{~A}$ depicts the distributions of these transcript groups $\left(\mathrm{T}_{\mathrm{FED}}>\right.$ $\mathrm{S}_{\mathrm{FED}}$ and $\mathrm{T}_{\mathrm{FED}}<\mathrm{S}_{\mathrm{FED}}$ ) with regard to BINs. A strikingly higher percentage of transcripts of the $\mathrm{T}_{\mathrm{FED}}<\mathrm{S}_{\mathrm{FED}}-$ group were present in the BINs related to signalling, cell, DNA, stress, and cell wall formation compared with the $\mathrm{T}_{\mathrm{FED}}>\mathrm{S}_{\mathrm{FED}}$-group. The BINs RNA and photosynthesis showed the opposite trend (Figure 1A).

Both transcript groups $\left(\mathrm{T}_{\mathrm{FED}}>\mathrm{S}_{\mathrm{FED}}\right.$ and $\left.\mathrm{T}_{\mathrm{FED}}<\mathrm{S}_{\mathrm{FED}}\right)$ were further analysed for a statistical over-representation of specific BINs compared to the $Q$. robur reference set that was used for transcript mapping. In the $\mathrm{T}_{\mathrm{FED}}>\mathrm{S}_{\mathrm{FED}^{-}}$

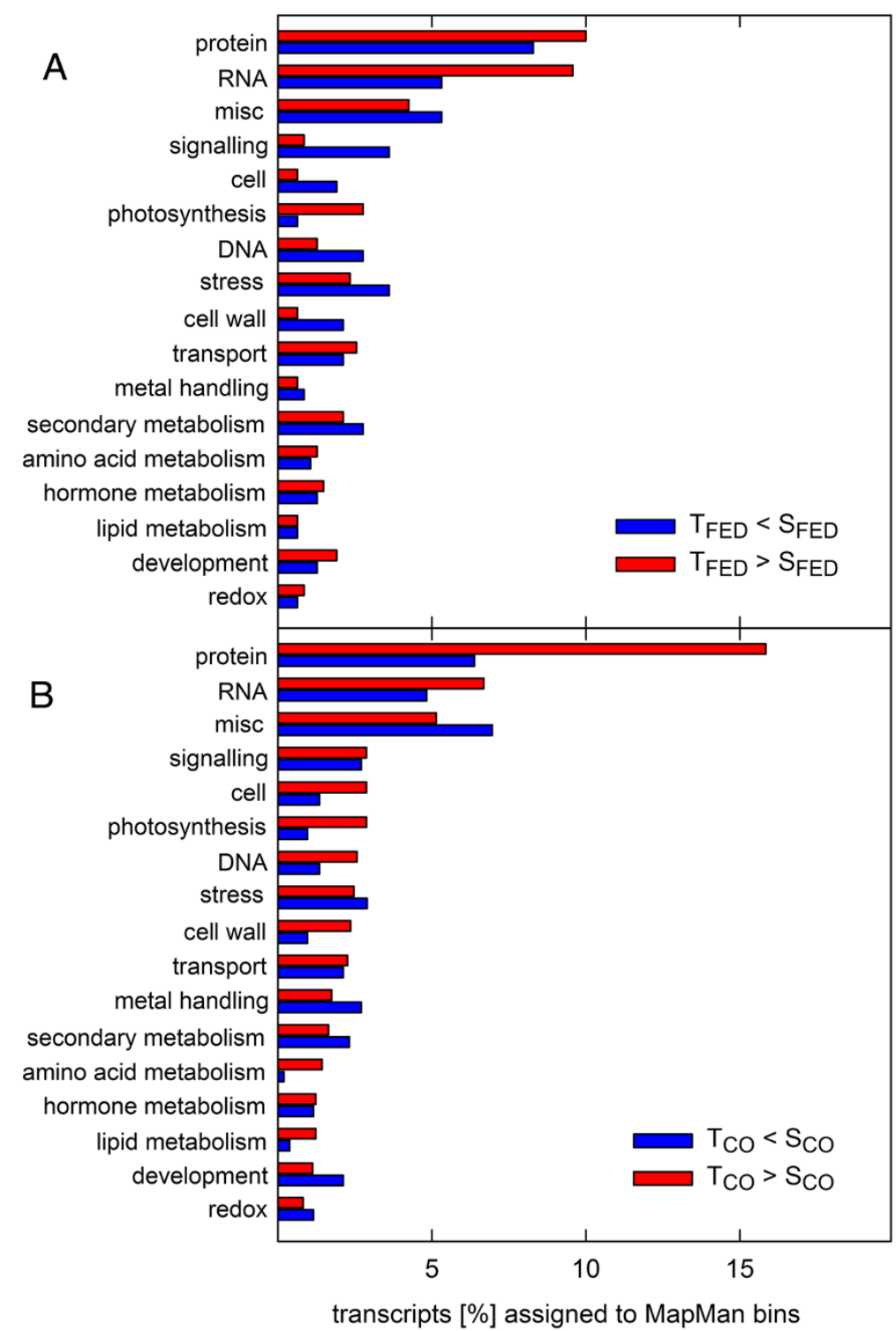

Figure 1 Functional composition of the different candidate transcript groups. Transcripts from the $T_{F E D}>S_{F E D}-\left(\right.$ red) and $T_{F E D}<S_{F E D}-(b l u e)$ groups (A) and $\mathrm{T}_{\mathrm{CO}}>\mathrm{S}_{\mathrm{CO}^{-}}(\mathrm{red})$ and $\mathrm{T}_{\mathrm{CO}}<\mathrm{S}_{\mathrm{CO}^{-}}$(blue) groups (B) were assigned to MapMan BINs and transcripts per BIN were counted (counts in $\%$ of total transcript counts in the candidate group on the X-axes). Only MapMan BINs showing at least 3 members in all groups were displayed. Unassigned transcripts were not displayed. CO, control sample; FED, fed sample. 
group, the RNA synthesis and short chain dehydrogenase/reductase BINs were significantly over-represented compared to the reference set (Figure 2). In contrast, the DNA BIN and the chromatin structure-related histone $\mathrm{BIN}$ were over-represented in the $\mathrm{T}_{\mathrm{FED}}<\mathrm{S}_{\mathrm{FED}}$-group (Figure 2).

\section{Constitutive transcriptional differences between T- and S-oaks}

To elucidate the potential differences between the constitutive transcript profiles of $\mathrm{T}$ - and S-oaks, we compared the transcript expression values between unfed T- and S-oak control samples. Although these samples represent pooled samples of different $\mathrm{S}$ - and T-oak individuals, one has to consider that some of the differentially expressed genes identified from this comparison between $\mathrm{S}$ - and T-oak controls would contribute to other phenotypic differences than resistance to the green oak leaf roller.

Considering all transcripts with any difference in the values between the samples, 28 BINs were identified that showed expression differences that deviated from those of all other BINs (Additional file 1). Among these BINs were the E3 (E3 ubiquitin ligase) BIN and the flavo- noids BIN, which are related to secondary metabolism (Additional file 2).

In total, 1,464 transcripts showed constitutively different expression levels. Of these, 955 transcripts had higher expression levels in T-oaks compared to S-oaks $\left(\mathrm{T}_{\mathrm{CO}}>\mathrm{S}_{\mathrm{CO}} ; \log 2\right.$ fold change $\left.\geq 1.5\right)$, while 509 transcripts had lower expression levels $\left(\mathrm{T}_{\mathrm{CO}}<\mathrm{S}_{\mathrm{CO}}\right.$; log2 fold change $\leq-1.5$; Additional file 3 ). It is obvious at first glance that a much higher percentage of the $\mathrm{T}_{\mathrm{CO}}>$ $\mathrm{S}_{\mathrm{CO}}$-group transcripts (red bars) were present in the protein BIN compared with those of the $\mathrm{T}_{\mathrm{CO}}<\mathrm{S}_{\mathrm{CO}^{-}}$ group (blue bars; Figure 1B). The same trend in distribution was also observed for the cell, photosynthesis, DNA, cell wall, amino acid metabolism, and lipid metabolism BINs (Figure 1B). It is interesting to note that the cell, DNA, and cell wall BINs showed an inverse profile of transcript enrichment in the insect-fed leaves (Figure 1A).

When we analysed the enrichment of specific BINs in the $\mathrm{T}_{\mathrm{CO}}>\mathrm{S}_{\mathrm{CO}}$-group compared to the $Q$. robur reference set, we observed that several BINs showed significant over-representation (Figure 2); among these were many protein synthesis-related BINs. With regard to secondary metabolism, the farnesyl pyrophosphate synthetase BIN

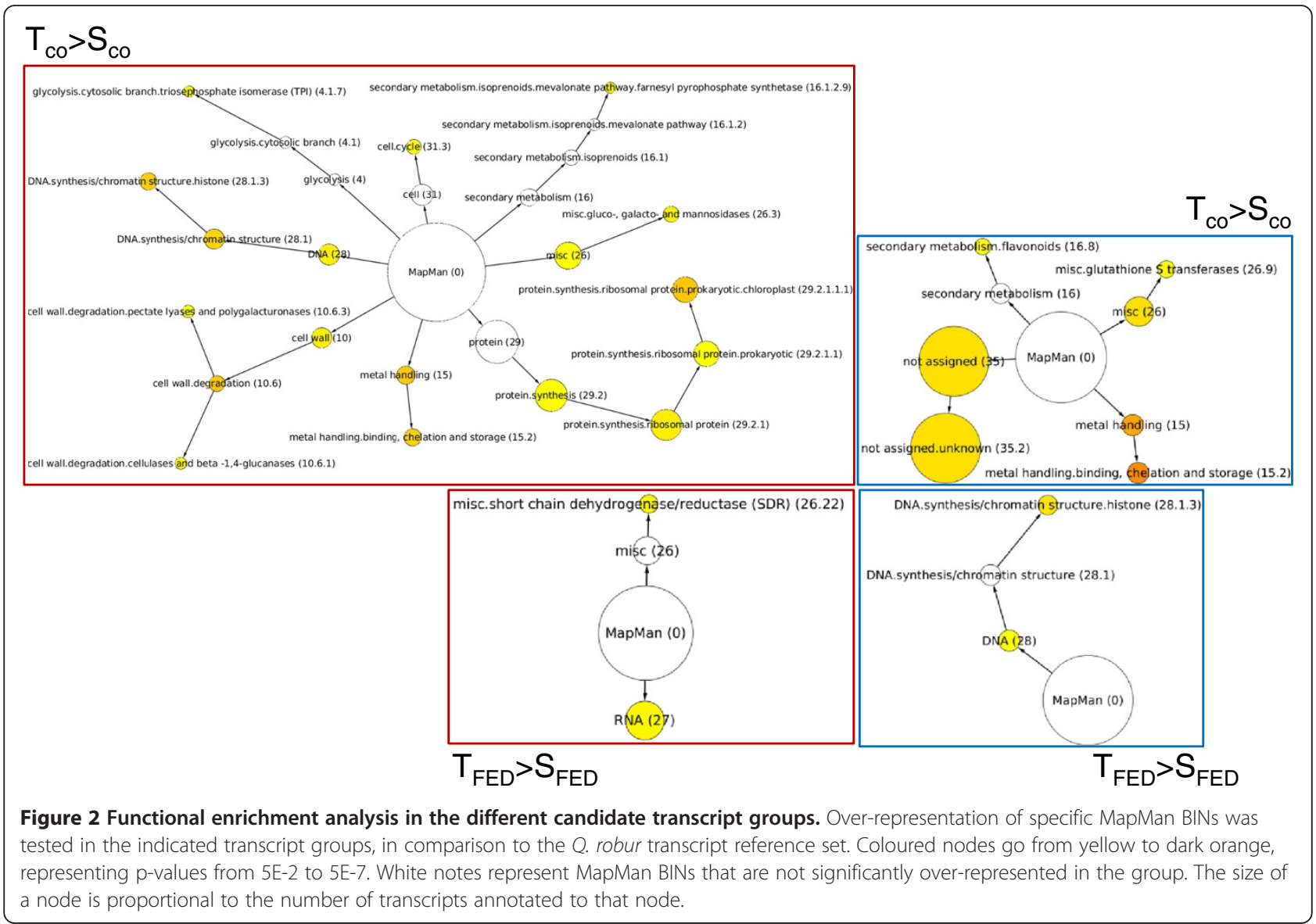


of the cytosolic isoprenoid pathway was also overrepresented in this group. Two BINs related to cell wall degradation, were also over-represented in the $\mathrm{T}_{\mathrm{CO}}>$ $\mathrm{S}_{\mathrm{CO}}$-group: (i) the pectate lyases and polygalacturonases BIN and (ii) the cellulases and beta-1,4-glucanases BIN (Figure 2). In the $\mathrm{T}_{\mathrm{CO}}<\mathrm{S}_{\mathrm{CO}}$-group, transcripts corresponding to glutathione-S-transferases and metal handling (especially metal binding, chelation, and storage) showed an over-representation. With regard to secondary metabolism, we observed a significant enrichment of transcripts related to flavonoid backbone biosynthesis in this group ( $\mathrm{p}<0.05$; Figure 2 ).

Table $1\left(\mathrm{~T}_{\mathrm{CO}}>\mathrm{S}_{\mathrm{CO}}\right)$ and Table $2\left(\mathrm{~T}_{\mathrm{CO}}<\mathrm{S}_{\mathrm{CO}}\right)$ summarise the 10 most differentially expressed transcripts in each group (Related sequences in Additional file 4). We observed dramatically higher expression levels in the T-controls than in the S-controls (log2 fold change $>6.5$ ) for transcripts weakly similar to Arabidopsis thaliana transcripts encoding PDF1 (protodermal factor 1; 71\% maximum amino acid identity), a protein phosphatase $2 \mathrm{C}$ family protein $(70 \%$ maximum amino acid identity), and a GDSL-motif lipase/ hydrolase family protein $(50 \%$ maximum amino acid identity; Table 1). Lower expression levels in T-controls compared to $\mathrm{S}$-controls ( $\log 2$ fold change $<-6.5$ ) were detected for transcripts moderately similar to A. thaliana transcripts encoding the ubiquitin extension protein 1 (ERD16, Early Response to Dehydration 1; 99\% maximum amino acid identity) and osmotin 34 (69\% maximum amino acid identity; Table 2).

\section{Transcriptional responses induced by $T$. viridana feeding in $\mathrm{T}$ - and S-oaks}

After comparing the transcript profiles of fed and unfed $\mathrm{T}$ - and S-oaks, we were interested in the transcriptional responses of $\mathrm{T}$ - and $\mathrm{S}$-oaks that were induced by $T$. viridana feeding. As the expression values from the fed samples were derived from a different type of Solexa reads (36 bp single-end reads) than the expression values from the controls (101 bp single-end reads), this bioinformatic analysis has to be interpreted carefully. Nevertheless, we obtained a general overview of the cellular functions involved in the defence responses of Q. robur to $T$. viridana and identified additional differences between the oak types.

Table 1 Top10-transcripts of the Tco > Sco-group with known functional MapMan annotation

\begin{tabular}{|c|c|c|c|c|c|}
\hline Identifier & MapMan sub-bin & $\begin{array}{l}\text { Putative function according Mercator } \\
\text { (score of the blast hit in italics) }\end{array}$ & $\begin{array}{l}\text { RPKM } \\
\mathrm{T}_{\text {CO }}\end{array}$ & $\begin{array}{l}\text { RPKM } \\
\text { S }_{\text {CO }}\end{array}$ & $\begin{array}{l}\text { Log } 2 \text { fold } \\
T_{\mathrm{CO}} / \mathrm{S}_{\mathrm{CO}}\end{array}$ \\
\hline WZ0AQRAP12YP16FM1 & development. unspecified & $\begin{array}{l}\text { weakly similar (129) to AT2G42840 PDF1 } \\
\text { (PROTODERMAL FACTOR 1) }\end{array}$ & 11.5 & 0.0 & 9.4 \\
\hline WZ0AQRAP12YM18FM1 & protein. post-translational modification & $\begin{array}{l}\text { weakly similar to (182) AT4G38520 protein } \\
\text { phosphatase 2C family protein / PP2C } \\
\text { family protein }\end{array}$ & 31.3 & 0.1 & 8,5 \\
\hline Gnl|UG|Qro\#S57156573 & misc. GDSL-motif lipase & $\begin{array}{l}\text { weakly similar (180) to AT4G18970 GDSL- } \\
\text { motif lipase/ hydrolase family protein }\end{array}$ & 3.7 & 0.0 & 6.8 \\
\hline Gnl|UG|Qro\#S57132810 & $\begin{array}{l}\text { misc. protease inhibitor/ seed storage/ } \\
\text { lipid transfer protein (LTP) family protein }\end{array}$ & $\begin{array}{l}\text { weakly similar (170) to AT2G45180 protease } \\
\text { inhibitor/seed storage/lipid transfer protein } \\
\text { (LTP) family protein weakly similar (145) to } \\
\text { 14KD_DAUCA } 14 \mathrm{kDa} \text { proline-rich protein } \\
\text { DC2.15 precursor - Daucus carota }\end{array}$ & 6.4 & 0.1 & 6.7 \\
\hline WZ0AQRAQ11YF07FM1 & $\begin{array}{l}\text { DNA. synthesis/ chromatin structure. } \\
\text { histone }\end{array}$ & $\begin{array}{l}\text { weakly similar (159) to AT5G59910 HTB4; } \\
\text { DNA binding | weakly similar (160) to } \\
\text { H2B_GOSHI Histone H2B - Gossypium hirsutum }\end{array}$ & 27.4 & 0.3 & 6.6 \\
\hline Gnl|UG|Qro\#S57098114 & protein. degradation. serine protease & $\begin{array}{l}\text { moderately similar (392) to AT4G17040 } \\
\text { ATP-dependent Clp protease proteolytic } \\
\text { subunit, putative weakly similar (106) to } \\
\text { CLPP_CHLVU ATP-dependent Clp protease } \\
\text { proteolytic subunit (EC3.4.21.92) }\end{array}$ & 5.0 & 0.1 & 6.6 \\
\hline Gnl|UG|Qro\#S57144797 & $\begin{array}{l}\text { RNA. regulation of transcription. } \\
\text { MYB-related transcription } \\
\text { factor family }\end{array}$ & $\begin{array}{l}\text { weakly similar (191) to AT1G74840 myb } \\
\text { family transcription factor }\end{array}$ & 13.9 & 0.2 & 6.4 \\
\hline Gnl|UG|Qro\#S57095514 & $\begin{array}{l}\text { cell wall. degradation. } \\
\text { cellulases and beta -1, 4-glucanases }\end{array}$ & $\begin{array}{l}\text { moderately similar (314) to AT1G70710 CEL1, } \\
\text { ATGH9B1 (ARABIDOPSIS THALIANA GLYCOSYL } \\
\text { HYDROLASE 9B1); cellulase/ hydrolase, hydrolysing } \\
\text { O-glycosyl compounds }\end{array}$ & 15.9 & 0.2 & 6.3 \\
\hline WZ0AQRAP12YB01FM1 & RNA. processing. ribonucleases & $\begin{array}{l}\text { weakly similar (182) to MAL11_MALDO Major } \\
\text { allergen Mal d } 1 \text { (Mal d I) - Malus domestica }\end{array}$ & 40.8 & 0.8 & 5.7 \\
\hline WZ0AQRAP10YM20FM1 & stress. abiotic. unspecified & $\begin{array}{l}\text { moderately similar to (237) AT3G05950; } \\
\text { germin-like protein, putative }\end{array}$ & 0.9 & 0.0 & 5.6 \\
\hline
\end{tabular}


Table 2 Top10-transcripts of the Tco < Sco-group with known functional MapMan annotation

\begin{tabular}{|c|c|c|c|c|c|}
\hline Identifier & MapMan subbin & $\begin{array}{l}\text { Putative function according Mercator } \\
\text { (score of the blast hit in italics) }\end{array}$ & $\begin{array}{l}\text { RPKM } \\
\mathrm{T}_{\mathrm{CO}} \\
\end{array}$ & $\begin{array}{l}\mathrm{RPKM} \\
\mathrm{S}_{\mathrm{CO}}\end{array}$ & $\begin{array}{l}\log 2 \text { fold } \\
\mathrm{T}_{\mathrm{CO}} / \mathrm{S}_{\mathrm{CO}}\end{array}$ \\
\hline WZOAQRAQ11YC24FM1 & protein. degradation. ubiquitin & $\begin{array}{l}\text { moderately similar (257) to AT3G52590 } \\
\text { UBQ1 (UBIQUITIN EXTENSION PROTEIN 1), } \\
\text { EMB2167, ERD16, HAP4 UBQ1; protein } \\
\text { binding / structural constituent of ribosome } \\
\text { weakly similar (150) to UBIQ_WHEAT Ubiquitin }\end{array}$ & 0.2 & 396.7 & -10.8 \\
\hline Gnl|UG|Qro\#S57141407 & stress. biotic & $\begin{array}{l}\text { moderately similar (226) to AT4G11650 ATOSM34 } \\
\text { (osmotin 34) moderately similar (285) to } \\
\text { P21_SOYBN Protein P21 - Glycine max }\end{array}$ & 7.4 & 1514.8 & -7.7 \\
\hline Gnl|UG|Qro\#S57077753 & cell. organisation & $\begin{array}{l}\text { moderately similar (380) to AT5G12380 annexin, } \\
\text { putative moderately similar (471) to ANX4_FRAAN } \\
\text { Annexin-like protein RJ4 - Fragaria ananassa }\end{array}$ & 1.3 & 103.7 & -6.3 \\
\hline Gnl|UG|Qro\#S57131911 & $\begin{array}{l}\text { protein. synthesis. ribosomal protein. } \\
\text { eukaryotic. } 40 \text { S subunit.S8 }\end{array}$ & $\begin{array}{l}\text { moderately similar (297) to AT5G59240 } 40 \text { S } \\
\text { ribosomal protein S8 (RPS8B) moderately similar } \\
\text { (313) to RS8_MAIZE } 40 \text { S ribosomal protein } \\
\text { S8 - Zea mays }\end{array}$ & 0.2 & 12.2 & -5.7 \\
\hline Gnl|UG|Qro\#S57149481 & stress. abiotic. unspecified & $\begin{array}{l}\text { moderately similar (231) to AT5G53160 } \\
\text { unknown protein }\end{array}$ & 0.1 & 2.5 & -5.6 \\
\hline GnI|UG|Qro\#S57088372 & stress. biotic. PR-proteins & $\begin{array}{l}\text { weakly similar (134) to AT5G17680 disease } \\
\text { resistance protein (TIR-NBS-LRR class), putative }\end{array}$ & 0.7 & 13.7 & -4.3 \\
\hline Gnl|UG|Qro\#S57110966 & misc. peroxidases & $\begin{array}{l}\text { weakly similar (191) to AT5G51890 peroxidase } \\
\text { weakly similar to (188) PER2_ARAHY Cationic } \\
\text { peroxidase } 2 \text { precursor (EC 1.11.1.7; } \\
\text { PNPC2) - Arachis hypogaea }\end{array}$ & 0.1 & 1.0 & -4.2 \\
\hline Gnl|UG|Qro\#S57139400 & transport. sugars & $\begin{array}{l}\text { moderately similar (241) to AT4G36670 mannitol } \\
\text { transporter, putative weakly similar (109) to HEX6_ } \\
\text { RICCO Hexose carrier protein HEX6 - } \\
\text { Ricinus communis }\end{array}$ & 0.1 & 2.4 & -4.2 \\
\hline Gnl|UG|Qro\#S57094988 & $\begin{array}{l}\text { secondary metabolism. isoprenoids. } \\
\text { carotenoids. carotenoid cleavage } \\
\text { dioxygenase }\end{array}$ & $\begin{array}{l}\text { very weakly similar (87.8) to AT3G63520 CCD1 } \\
\text { (CAROTENOID CLEAVAGE DIOXYGENASE 1), } \\
\text { ATCCD1, ATNCED1, NCED1; 9-cis-epoxycarotenoid } \\
\text { dioxygenase }\end{array}$ & 0.3 & 5.8 & -4.1 \\
\hline gnl|UG|Qro\#S57087752 & protein. post-translational modification & $\begin{array}{l}\text { moderately similar to (294) AT3G51630 WNK5 } \\
\text { (WITH NO LYSINE (K) KINASE 5), ZIK1, ATWNK5; } \\
\text { protein kinase }\end{array}$ & 1.7 & 28.1 & -4.1 \\
\hline
\end{tabular}

Related sequences and GenBank accession numbers are available in Additional file 4.

All transcripts exhibiting an increase or decrease in their expression value after feeding (log2 fold change $>0$ or $<0$ ), compared to the corresponding unfed controls were considered in a MapMan analysis. In total, 48 BINs showed significant different average BIN responses compared to the response of all other BINs in both $\mathrm{T}$ - and S-oaks $(\mathrm{p}<0.05$, Wilcoxon rank sum test in the MapMan tool; Additional files 1 and 2). Among these were BINS related to the light reaction of photosynthesis, to the synthesis of prokaryotic and eukaryotic ribosomal proteins and to abiotic stress (Additional file 2 ). Changes in chromatin structure, especially in the associated histones indicate an involvement of epigenetic transcriptional regulation in the host defence (Additional file 2).

BINs that exhibited significant differences only in T-oaks comprised, among others, those related to cell wall degradation, GDSL-motif lipases, and protein targeting to the secretory pathway (Additional file 2). In S-oaks, the BINs related to steroid synthesis, squalene metabolism, metal handling, E3 ubiquitin ligases, and redox regulation were among those with a significant different BIN response.

We further identified groups of up- or down-regulated transcripts after $T$. viridana feeding by comparing the expression values between the different treatments. Considerably more transcripts showed an up-regulation (2,932 transcripts; $\log 2$ fold change $\geq 1.5)$ than showed a down-regulation (1,177 transcripts; log2 fold change $\leq-1.5$ ) after T. viridana feeding in both T- and S-oaks (Additional file 3). The expression value changes (up- or down-regulation) that were induced by $T$. viridana feeding in both $\mathrm{T}$ - and S-oaks were mapped to the 'Biotic stress' drawing in MapMan, which represents transcripts that may be involved in biotic stress (Figure 3). Most of the induced transcripts were assigned to BINS related to proteolysis, signalling, abiotic stress, cell wall, secondary metabolites, redox state, and heat shock protein. With regard to hormone signalling, 


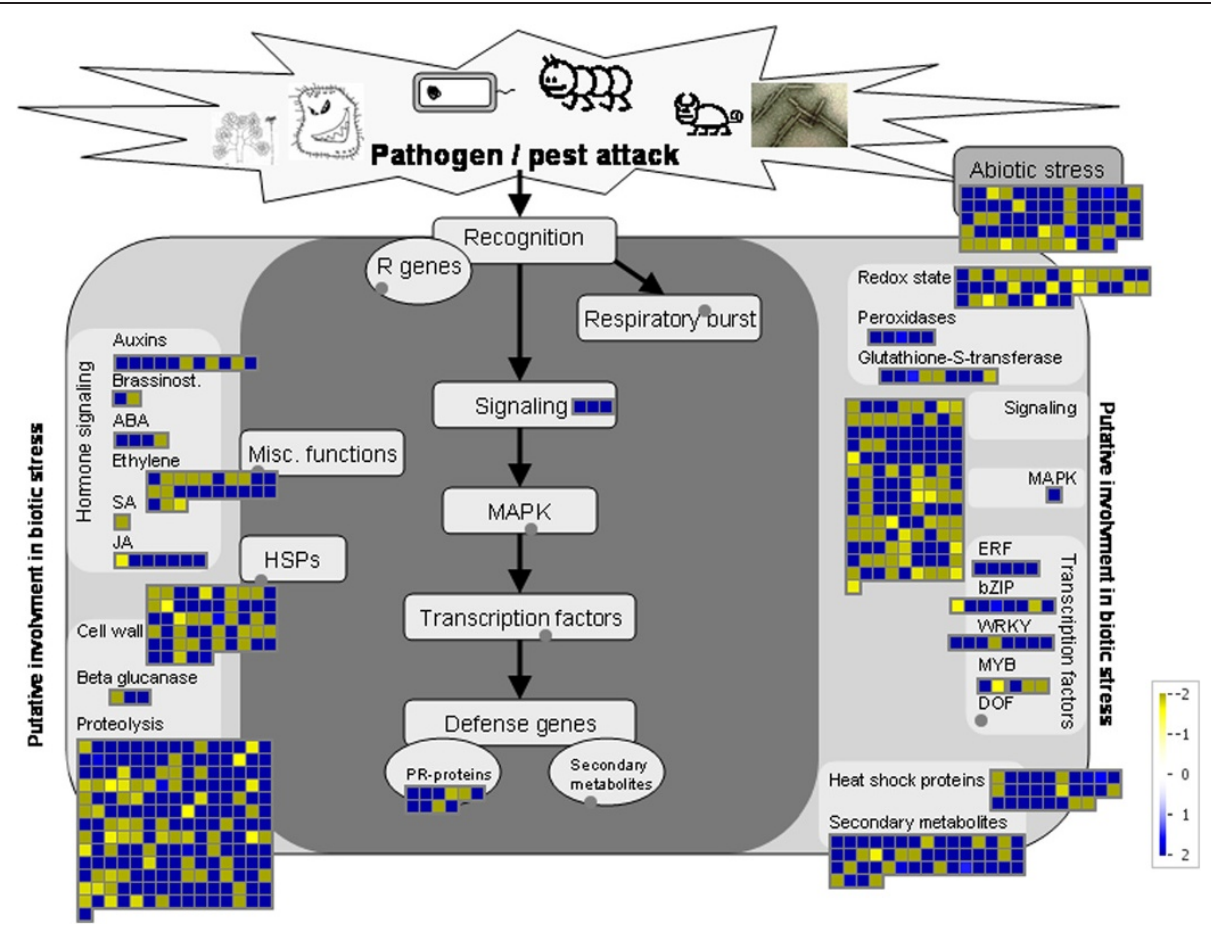

Figure 3 Transcriptional changes induced by T. viridana feeding in both T- and S-oaks. All transcripts induced by T. viridana feeding in both T- and S-oaks were mapped to the 'Biotic stress' drawing in the MapMan tool [30]. Blue boxes, transcripts up-regulated after feeding in both T- and S-oaks ( $T_{\text {IND }}>=1.5$ and $S_{\text {IND }}>=1.5$; mean value of $T_{\text {IND }}$ and $S_{\text {IND }}$ was mapped); yellow boxes, transcripts down-regulated after feeding in both $\mathrm{T}$ - and $\mathrm{S}$-oaks ( $\mathrm{T}_{\mathrm{IND}}<=-1.5$ and $\mathrm{S}_{\mathrm{IND}}<=-1.5$; mean value of $\mathrm{T}_{\text {IND }}$ and $\mathrm{S}_{\mathrm{IND}}$ was mapped). Dots representing putative metabolites appear in grey as no related data were mapped.

transcripts assigned to ethylene, auxin, and jasmonate BINs were the most mapped transcripts. Most of the transcripts assigned to jasmonate, peroxidases, ERF (ethylene-responsive factors) and WRKY transcription factor BINs were up-regulated by $T$. viridana feeding in both T- and S-oaks (Figure 3).

Transcripts expressing putative cell-wall-degrading enzymes We observed an enrichment of transcripts encoding cell wall-degrading enzymes in the $\mathrm{T}_{\mathrm{CO}}>\mathrm{S}_{\mathrm{CO}}$ group. In particular, the abundance of pectate lyase and polygalacturonase transcripts, in addition to cellulase and beta-1, 4-glucanase gene transcripts, was increased (Figure 2). Thus, we became specifically interested in the differences in the expression of these transcripts between T- and S-oaks.

Figure 4 shows the expression values of all transcripts that were assigned to the cell wall degradation BIN and that exceeded a specific expression value in the T-oak controls (red bars) and S-oak controls (blue bars). Most of the transcripts showed higher expression values in T-oaks than in S-oaks (Figure 4; all transcripts with clearly higher expression in T-oaks compared to $\mathrm{S}$-oaks were marked by a star; $\log 2$ fold change $\geq 1.5$ ).

\section{Experimental validation of differential expression of candidate genes by PCR}

Five genes with different expression levels for T- and Soaks, namely, genes expressing a putative serine kinase, osmotin 34, HSP81 (a heat shock protein), CEL1 (a beat1,4-glucanase), a putative sesquiterpene synthase, and the housekeeping gene ARP4 (encoding a putative actinrelated protein), were chosen for a PCR-based validation of their expression (Table 3; related sequences in Additional file 4). The serine kinase (SerKi) showed a high constitutive expression value in $\mathrm{S}$-oaks $\left(\mathrm{S}_{\mathrm{CO}}\right)$ and an equally strikingly low expression value in both fed $\left(\mathrm{T}_{\mathrm{FED}}\right)$ and control $\left(\mathrm{T}_{\mathrm{CO}}\right)$ T-oaks (Table 3, Figure 5). Osmotin 34 (OSM34) was chosen for its combination of an extremely high constitutive expression value in $\mathrm{S}_{\mathrm{CO}}$, a high expression value in $\mathrm{S}_{\mathrm{FED}}$, and low expression values in both fed $\left(\mathrm{T}_{\mathrm{FED}}\right)$ and control $\left(\mathrm{T}_{\mathrm{CO}}\right)$ T-oaks (Tables 2 and 3, Figure 5). The expression levels of HSP81 were also high in S-oaks $\left(\mathrm{S}_{\mathrm{CO}}\right.$ and $\left.\mathrm{S}_{\mathrm{FED}}\right)$ and low in T-oaks $\left(\mathrm{T}_{\mathrm{CO}}\right.$ and $\mathrm{T}_{\mathrm{FED}}$; Table 3; Figure 5). To represent genes with a high constitutive expression value in $\mathrm{T}_{\mathrm{CO}}$ and a slightly increased expression value in $\mathrm{S}_{\mathrm{FED}}$, the beta-1,4-glucanase gene CEL1 (BGlu1) was used (Tables 1 and 3, Figure 5). Finally, a sesquiterpene synthase (TPS) showed very low constitutive expression values in $\mathrm{S}_{\mathrm{CO}}$ but had high expression values in both 


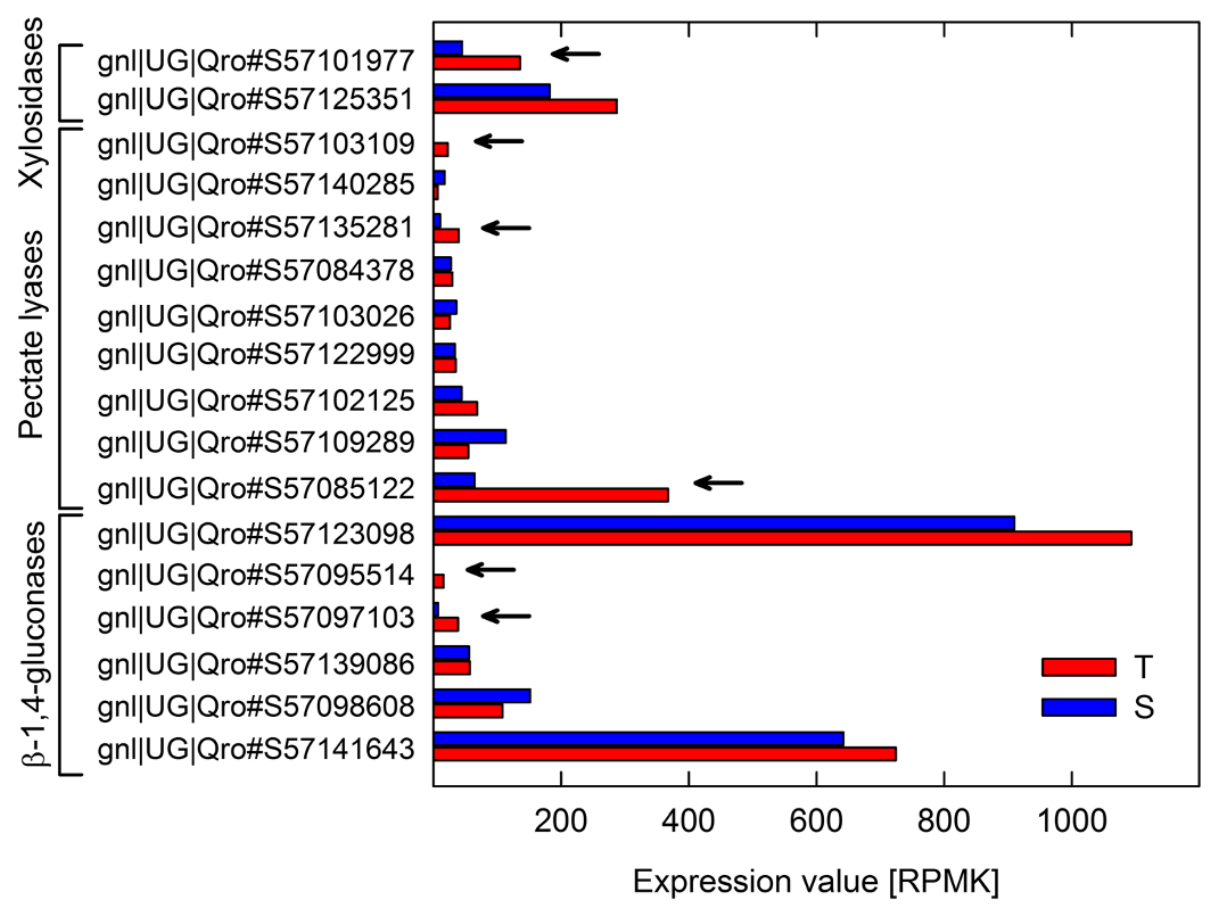

Figure 4 Transcript levels of cell wall degrading enzymes in T- and S-oak controls. Expression values (RPKM) of transcripts assigned by MapMan to the cell wall degradation BIN are presented for T-oak controls (red) and S-oak controls (blue). Only transcripts where the sum of RPKM values of T- and S-oak controls was at least 10 are presented. Arrows mark transcripts with log2 fold changes $\geq 1.5$ when comparing expression values of T- with S-oak controls.

$\mathrm{T}_{\mathrm{CO}}$ and $\mathrm{T}_{\mathrm{FED}}$ and slightly increased expression values in $\mathrm{S}_{\mathrm{FED}}$ (Table 3, Figure 5).

\section{Metabolomic differences between T- and S-oaks after}

\section{T. viridana feeding}

Principal components analysis (PCA) identified clear metabolic differences between T- and S-oaks at $32 \mathrm{~h}$ after the onset of feeding by $T$. viridana larvae (Figure 6) by explaining a total of $15 \%$ of the variance in metabolites differences. Furthermore, the distinct metabolic profiles of intact (I) and directly damaged (D) leaves showed that local and/or systemic defence responses were induced in the plant within $32 \mathrm{~h}$ of herbivore feeding.

To gain insights into the compounds correlated with each group, we performed a discriminant partial least squares regression (PLSR) analysis (data not shown) and annotated the significant discriminant masses (Martens test) using the KEGG, LMPK, HMDB, and ChemSpider databases (Additional file 5). The identified metabolites showed a distinct metabolic accumulation that was characteristic of their metabolic pathway and cluster group (Figure 7A). In general, we found that 110 metabolites were either up- or down-regulated in the two different

Table 3 Expression values of candidate genes used for semi-quantitative PCR

\begin{tabular}{|c|c|c|c|c|c|c|}
\hline \multirow[t]{2}{*}{ Identifier } & \multirow{2}{*}{$\begin{array}{l}\text { Gene } \\
\text { name }\end{array}$} & \multicolumn{4}{|c|}{ Expression values (RPKMs) } & \multirow{2}{*}{$\begin{array}{l}\text { ng DNA } \\
\text { for PCR }\end{array}$} \\
\hline & & $\mathrm{T}_{\mathrm{CO}}$ & $\mathrm{S}_{\mathrm{CO}}$ & $\mathrm{T}_{\mathrm{FED}}$ & $\mathrm{S}_{\mathrm{FED}}$ & \\
\hline gnl||UG|Qro\#S57094678 & SerKi & 9 & 41 & 9 & 12 & 10 \\
\hline gnl|UG|Qro\#S57141407 & OSM34 & 7.4 & 1514.8 & 8.4 & 362.9 & 2 \\
\hline gnl|UG|Qro\#S57133728 & HSP81 & 1.1 & 16.6 & 2.1 & 6.7 & 10 \\
\hline gnl|UG|Qro\#S57095514 & BGlu1 & 15.9 & 0.2 & 2.78 & 3.6 & 6 \\
\hline $\begin{array}{l}\text { Qr_TPS_putative_terpene } \\
\text { synthase }\end{array}$ & $\mathrm{TPS}^{*}$ & 59.5 & 1.1 & 56.9 & 10.5 & 10 \\
\hline gnl|UG|Qro\#S57081658 & ARP4* $^{*}$ & 126.4 & 124.3 & 74.1 & 81.8 & 10 \\
\hline
\end{tabular}

Related sequences and GenBank accession numbers are available in Additional file 4.

$\mathrm{T}_{\mathrm{CO}}$, unfed control of T-oaks; $\mathrm{S}_{\mathrm{CO}}$, unfed control of S-oaks; $\mathrm{T}_{\mathrm{FED}}$, fed T-oaks; $\mathrm{S}_{\mathrm{FED}}$, fed S-oaks. Asterisk at TPS and ARP4, mapping has been performed later than for the other candidates. 


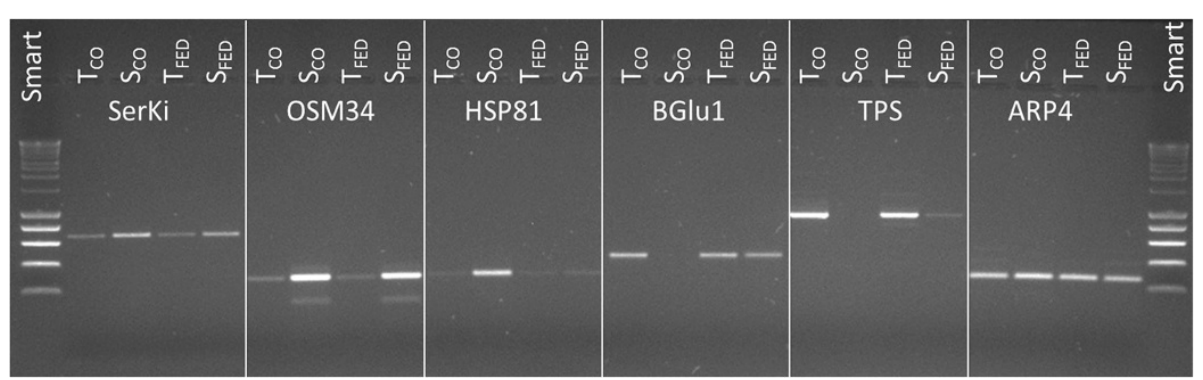

Figure 5 Validation of candidate genes. Agarose gel image of semi-quantitative PCR products of candidate genes. TCO, unfed control of T-oaks; $S_{C O}$, unfed control of S-oaks; $T_{F E D}$, fed T-oaks; $S_{F E D}$, fed S-oaks; Smart, used size ladder. For expression values (RPKM) and used amount of DNA see Table 3.

T- and S-oaks (Figure 7A, Additional file 5), which suggests that these metabolites might be good candidates for molecular biomarkers of the two T- and S-genotypes.

Each oak genotype displayed different levels of metabolites that could be grouped based on their KEGG classification [31] into metabolites belonging to amino acid, carbohydrate, cofactors, and vitamins, glycan, lipid, nucleotide, and secondary metabolism (terpenoid/ polyketide and other secondary metabolites, including alkaloids, flavones and flavonoids, and phenylpropanoid) classes (Figure 7A, Additional file 5). Among the metabolites showing strong differences in levels between $\mathrm{T}$ - and S-oaks, we focused our attention on the most abundant metabolites measured. Nicotinate ribonucleotide, an important precursor of nicotinamide adenine dinucleotide (NAD), was found to be strongly upregulated in T-oaks. Several end-products of secondary metabolism, particularly galloylated flavonol glycosides (of which kaempferol galloylgalactoside and quercetin

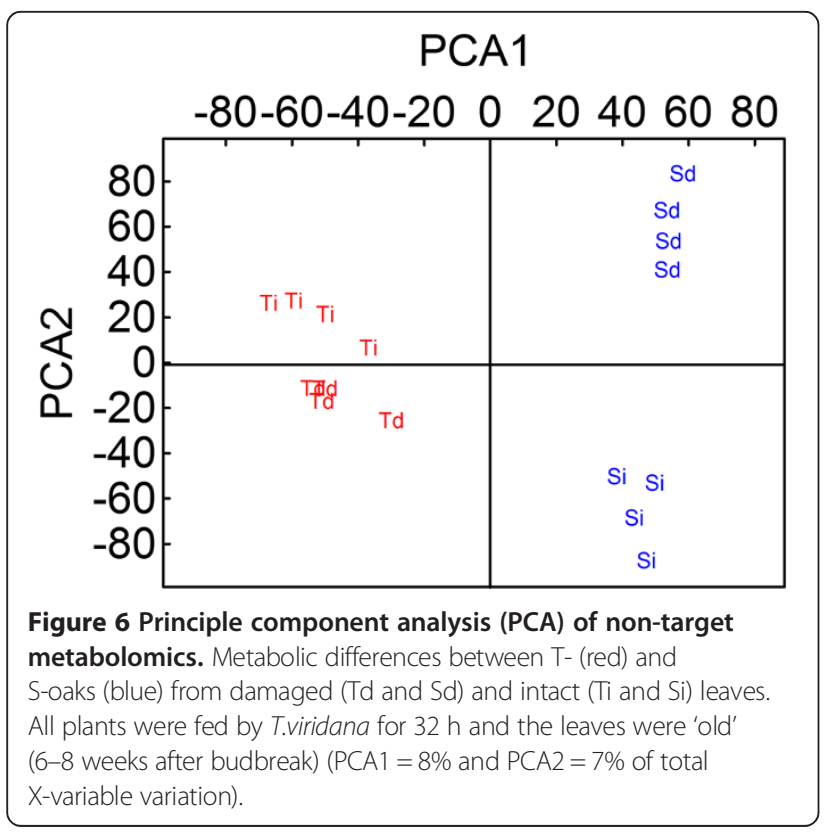

galloylglucoside were the most likely candidates among all potential isomers), were found to occur at levels that were 10 - to 20 -fold higher in T-oaks than in S-oaks. The amounts of these compounds did not differ between $\mathrm{D}$ and I leaves, which indicates that they likely show constitutive differences between T- and S-plants. The concentration of corilagin, a tannin and galloyl derivative, was higher in T-oaks. The amount of ellagic acid, another galloyl derivative typically found in oaks, was also greater in T-oaks. In addition, many biosynthetic precursors of condensed tannins were found at higher levels in T-oaks. Amongst these were flavan 3-ol derivatives, such as epigallocatechin, a catechin with an additional phenolic hydroxyl group. Additionally, some phenolic intermediates, such as coumaric acid, sinapoyl malate, coumaroyl quinic acid, were much more abundant in T-oaks than in S-oaks.

Conversely, S-oaks showed higher levels of basic flavonol glycosides. Luteolin glycoside, quercetin glycoside, and a methoxykaempferol glycoside were highly abundant in S-oak leaves (MS intensities $>10^{7}$ ) and also showed a greater relative difference between $\mathrm{T}$ - and S-oaks $\left(\log _{2}\right.$ $(\mathrm{T} / \mathrm{S})<-1$; Additional file 5). Additionally, free, unconjugated flavonols, such as luteolin and quercetin, showed relatively greater abundance in S-oaks than in T-oaks (Additional file 5, see also the next section).

In terms of lipid metabolism factors, the phospholipid glycerophosphoinositol was more abundant in T-oaks than in S-oaks. Conversely, the abundance of the glycerophosphodiester glycerophosphoglycerol was higher in S-oaks.

Globally, S-leaves showed higher levels of metabolites related to sugar metabolism, particularly the monosaccharides (e.g., rhamnose) and disaccharides (e.g., neohesperidose, sucrose), melibiitol from galactose metabolism, and different sugar intermediates (e.g., ribose 5-phosphate, xylose derivatives). T-oaks also contained higher amounts of other sugars, such as glucarate (an intermediate of ascorbate metabolism) and ribose 5-diphosphate, compared to S-oaks. Metabolites from nucleotide metabolism were significantly more abundant in S-oaks, which had 


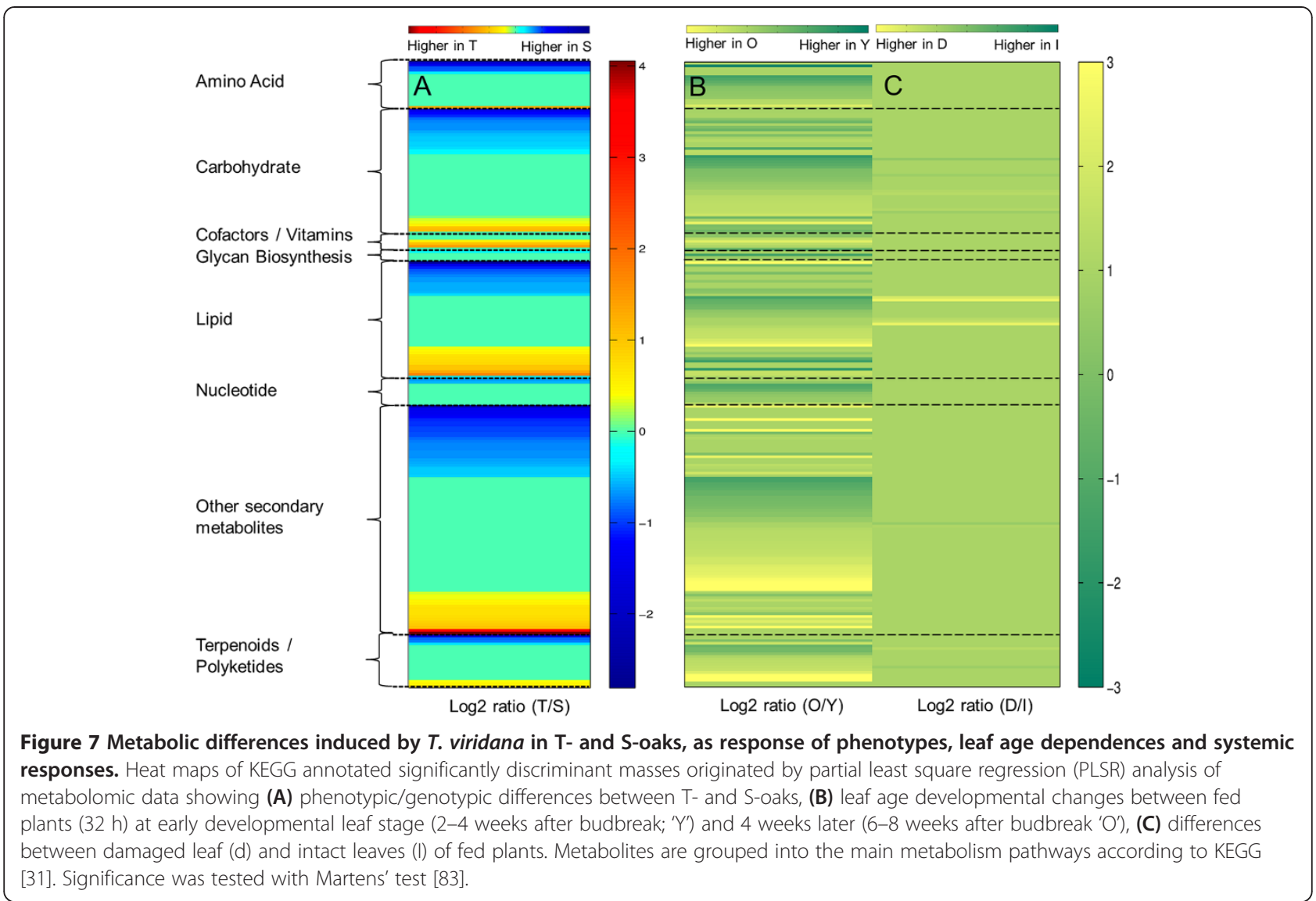

relatively high levels of cyclic adenosine monophosphate (cAMP) and cytidine monophosphate.

We could generally characterise the developmental changes in leaf metabolism using 169 metabolites that exhibited significantly altered expression in our study. Leaf maturation was associated with an increase in amino acids related to phenylalanine derivatives, while it was also associated with decreased levels of tryptophan, aspartic acid, and homoserine derivatives (Figure 7B, Additional file 5). Young leaves were rich in sugars, whereas older leaves showed a large accumulation of fatty acids (FA) that are related to herbivore defence (e.g., hallactone). Leaf development was also characterised by strong differences of the levels of specific flavonoids and phenolic compounds.

Local and systemic responses were indicated by significant changes in the levels of 14 metabolites between D- and I-leaves. Directly damaged leaves exhibited a greater accumulation of FA, FA oxidation products related to wounding responses, signalling compounds, and healing agents, such as traumatic acid, tuberonic acid, tuberonic acid glucoside, linolenic acid, and 13-L-hydroperoxylinoleic acid. Conversely, intact leaves had relative higher levels of carbohydrates and secondary metabolites (Figure 7C, Additional file 5).

\section{Combined mapping of metabolites and transcripts to metabolic pathways}

In an initial study [29], we described differences in the emission pattern of HIPVs among T- and S-oaks. T-oaks displayed higher emission rates of sesquiterpenes ( $\alpha$-farnesene and germacrene D), while the HIPV pattern of S-oaks was dominated by monoterpenes and the irregular acyclic homoterpene 4,8-dimethylnona-1,3,7-triene (DMNT), a derivative of the sesquiterpene nerolidol produced by oxidative degradation by a cytochrome P450 monooxygenase. Moreover, we found distinct differences in the phenolic compound composition of T- and S-oaks, and these differences were analysed in more detail, as described above. In the present analysis, we observed a significant enrichment of transcripts related to the biosynthesis of flavonoid backbones in the $\mathrm{T}_{\mathrm{CO}}<\mathrm{S}_{\mathrm{CO}}$-group (Figure 2). Moreover, there were significant changes detected in the flavonoids BIN as well as the related chalcones BIN when comparing all transcriptional differences between the T- and S-oak controls in MapMan (Additional file 1). To gain deeper insights into the regulation of these two metabolic pathways in both oak genotypes, a combined mapping of transcriptomic and metabolomic data to these pathways was performed.

Ratios ( $\log 2$ fold changes) of transcript expression values and mass intensities were mapped to the KEGG 
pathways of terpenoid and flavonoid backbone biosynthesis (Figures 8 and 9). The data clearly show an increase in the transcript levels of the plastidic 2C-methylD-erythritol 4-phosphate (MEP) pathway for isoprenoid biosynthesis in S-oaks compared to T-oaks (Figure 8, right panel). Only one transcript mapped specifically to the mevalonate pathway (Figure 8, left panel, blue box representing EC 1.1.1.34) with higher transcript levels in T-oaks compared to S-oaks. The other two transcripts that mapped, i.e., acetyl-CoA C-acetyltransferase (EC 2.3.1.9.) and hydroxymethylglutaryl-CoA synthase (EC 2.3.3.10), are known to be involved in several KEGG pathways.

Figure 9 summarizes the transcriptomic and metabolomic data with regard to flavonoid backbone biosynthesis. Most of the transcripts and metabolites showed higher levels in S-oaks compared to T-oaks, which indicates an increase in the biosynthesis of basic flavonoid compounds in S-oaks after T. viridana feeding. Only chalcone synthase (EC 2.3.1.74; EC 2.3.1.170), the first enzyme in the flavonoid pathway, was expressed at a higher level in T-oaks than in S-oaks (red boxes in Figure 9). The transcripts from this gene did not specifically map to flavonoid biosynthesis. Therefore, the specific contribution of the expressed transcript to flavonoid backbone biosynthesis cannot be deduced from the transcript data.

\section{Discussion}

In the present study, we aimed to discover the underlying genetic and metabolic basis for the differing susceptibilities of T- and S-oaks to T. viridana feeding.

Plant defence responses to herbivory are driven by both herbivore-induced factors (e.g., elicitors, effectors, wounding) and plant signalling (e.g., phytohormones and plant volatiles; Figure 10) [32]. Figure 10 summarizes the constitutive and induced transcriptomic and metabolomic differences in $\mathrm{T}$ - and $\mathrm{S}$-oaks responding to green oak leaf roller herbivory. The transcript levels of cell wall degrading enzymes (CWDE) are constitutively high in T-oaks (Figure 10A) but were found to be more inducible in S-oaks (Figure 10B). Changes in hormone signalling are likely to occur via the CDPK $\left(\mathrm{Ca}^{2+}\right.$-dependent protein kinases) and MAPK (mitogen-activated protein kinase) cascades. Moreover, transcriptional changes at transcription factor genes are most likely responsible for the eventual activation of several defence response genes, such as those involved in the synthesis of volatiles and pathogen-related genes (Figure 10). The activated cascade results in a different response in $\mathrm{T}$ - and $\mathrm{S}$-oaks mainly characterised by transcriptomic and metabolomic differences in the biosynthesis of tannins, flavonoids and terpenes (which is discussed in detail below).
The cell wall as the first barrier for invading herbivores

The plant cell wall is the first line of defence against invading pathogens and herbivores. Plants have evolved sensory mechanisms to detect pathogens and herbivores, including the indirect sensing of the impact of the invader on the host cell wall ('damaged self') [33,34]. In the present comparison, we discovered higher transcript levels of plant CWDEs (polygalacturonases and beta-1, 4-glucanases) in T-oak controls (Figure 10A), including increased levels of transcripts for the putative cellulase Cel1 (Figures 2 and 4; Table 1). At first glance, it is striking that T-oaks constitutively express higher levels of transcripts encoding enzymes that are normally inhibited by plants, e.g., by secreting polygalacturonase-inhibiting proteins, when being attacked by the polygalacturonases of a pathogen [35]. Conversely, cell wall-degrading enzymes may activate defence responses by releasing oligosaccharides as elicitors. Thus, the increased expression of several beta-1,4-glucanase genes, such as CEL1, in T-oaks (Tables 1 and 3; Figures 4, 5 and 10A) may result in higher constitutive levels of oligosaccharides. Additionally, cellulose-derived oligosaccharides have been shown to act as elicitors [36]. So far, there are no reports on the influence of higher constitutive expression levels of plant beta-1,4-glucanases and polygalacturonases on pathogen resistance. However, it was shown that tobacco and Arabidopsis plants expressing a fungal polygalacturonase are more resistant to microbial pathogens and have constitutively activated defence responses [37].

\section{Oxidative burst, protein phosphorylation signalling and hormone signalling}

Beyond the cell wall, the response cascade continues within the cell membrane (Figure 10). Oral secretions from herbivores can initiate plant cell trans-membrane potential (Vm) depolarization, an early response to herbivore feeding that is associated with the opening of voltage-dependent $\mathrm{Ca}^{2+}$ channels, changes in the intracellular $\mathrm{Ca}^{2+}$ concentration and the generation of reactive oxygen species (ROS), such as $\mathrm{H}_{2} \mathrm{O}_{2}$ (Figure 10B) [32,38]. Immediately after this event, protein phosphorylation signalling via mitogen-activated protein kinase (MAPK) cascades, as well as via calciumdependent kinases (CDPKs), triggers the production of phytohormones. After $T$. viridana feeding, we primarily observed the induction of transcripts associated with ethylene, jasmonic acid, and auxin production in both $\mathrm{T}$ - and S-oaks (Figures 3, 10). Genes related to jasmonic acid (JA) formation, for example, are already constitutively expressed at high levels (Figure 10A) and exhibit greater induction in S-oaks than in T-oaks (Figure 10B).

\section{Transcriptional differences in transcription factor genes and histone genes}

Hormone signalling may also trigger transcriptional changes at transcription factor genes (Figure 10), which 


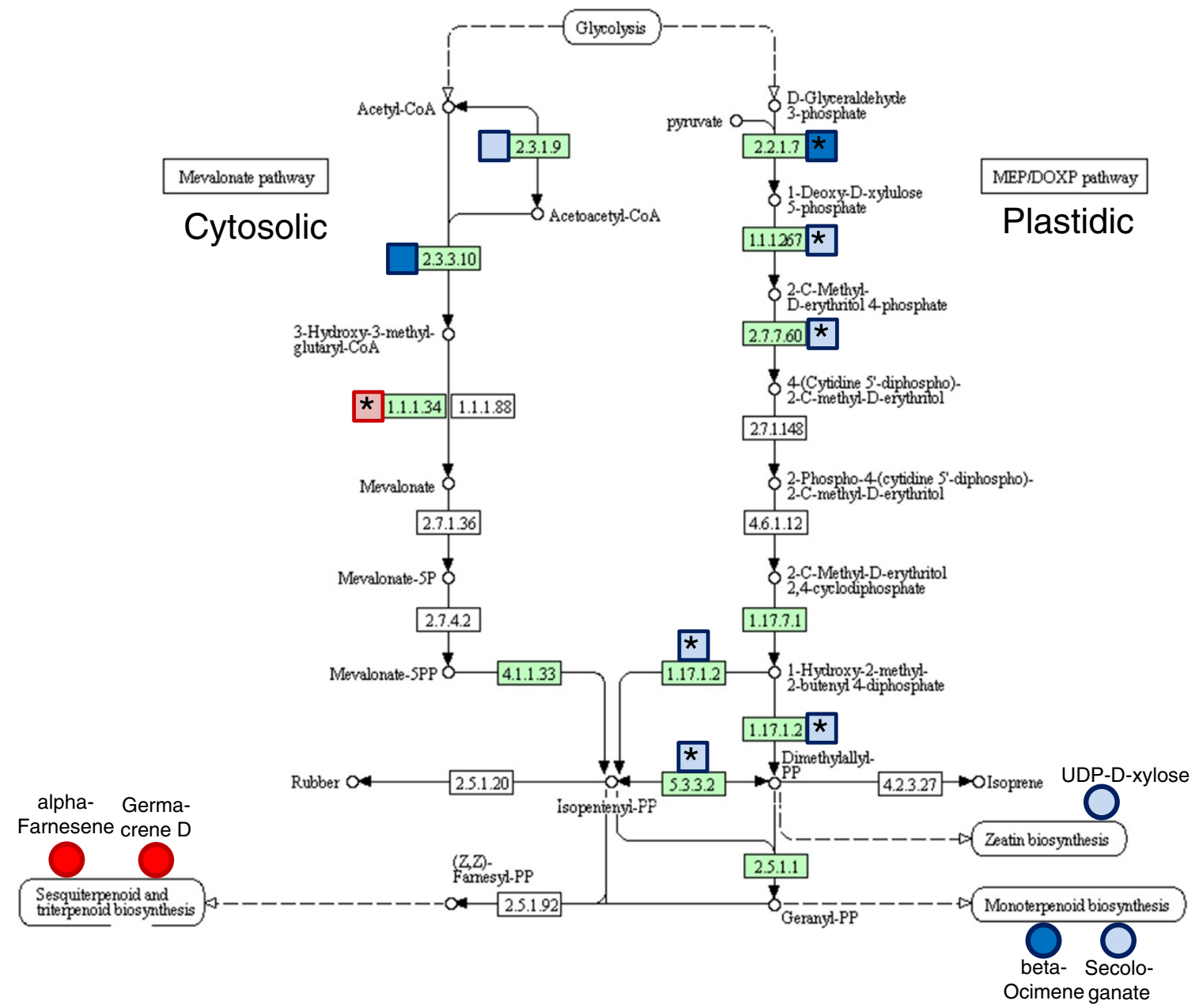

Figure 8 Combined mapping of transcriptomic and metabolomic data onto the KEGG reference pathway "terpenoid backbone biosynthesis". Log2 fold changes of RPKM ratios according to Additional file 5 and of mass intensities according to Additional file 4 were mapped on the KEGG reference pathway. Enzymes highlighted in green are enzymes present in the Q. robur reference transcript set that was used for as a reference for quantification of the transcript data. Log2 fold changes of alpha-Farnesene, Germacrene D, and beta-Ocimene were taken from Ghirardo et al. [29]. Boxes/circles in light red, $T_{\text {FED }}>S_{\text {FED }}(0.2 \leq \log 2$ fold change of RPKM/mass intensity ratio $<1.0)$; boxes/circles in dark red, $T_{F E D}>>S_{F E D}$ (log2 fold change of RPKM/mass intensity ratio $\geq 1.0$ ); boxes/circles in light blue, $T_{F E D}<S_{F E D}(-1<\log 2$ fold change of $\mathrm{RPKM}$ /mass intensity ratio $\leq-0.2$ ); boxes/circles in dark blue, $\mathrm{T}_{\mathrm{FED}}<<\mathrm{S}_{\mathrm{FED}}$ (log2 fold change of RPKM/mass intensity ratio $\leq-1.0$ ); big asterisk in the box, specific mapping of the transcript to the pathway "terpenoid backbone biosynthesis"; no asterisk in the box, unspecific mapping of the transcript to several pathways.

in turn may activate different defence response genes (see next section). Differences in the constitutive and induced expression levels in $\mathrm{T}$ - and $\mathrm{S}$-oaks were observed for a number of transcription factors, including, e.g. several members of the ERF (ethylene-responsive factors) and WRKY transcription factor families (Figure 10).

Differences in the expression of genes related to DNA structure, especially histones, were highly apparent (Figure 10). Among the transcripts with higher constitutive expression levels in T-oaks compared to S-oaks, an enrichment of histone transcripts was obvious (Figure 2). For example, a transcript weakly similar to an A. thaliana histone 3B gene showed a distinctly higher level of expression in T-oaks (Tab. I). Functionally, DNA-associated histones may be involved in chromatin remodelling. Among the mechanisms of transcriptional regulation, chromatin remodelling accomplished through the activity of histone-modifying enzymes and ATP-dependent chromatin-remodelling complexes is emerging as a key process in the orchestration of plant biotic stress responses [39]. Whether the observed transcriptional differences in histones 


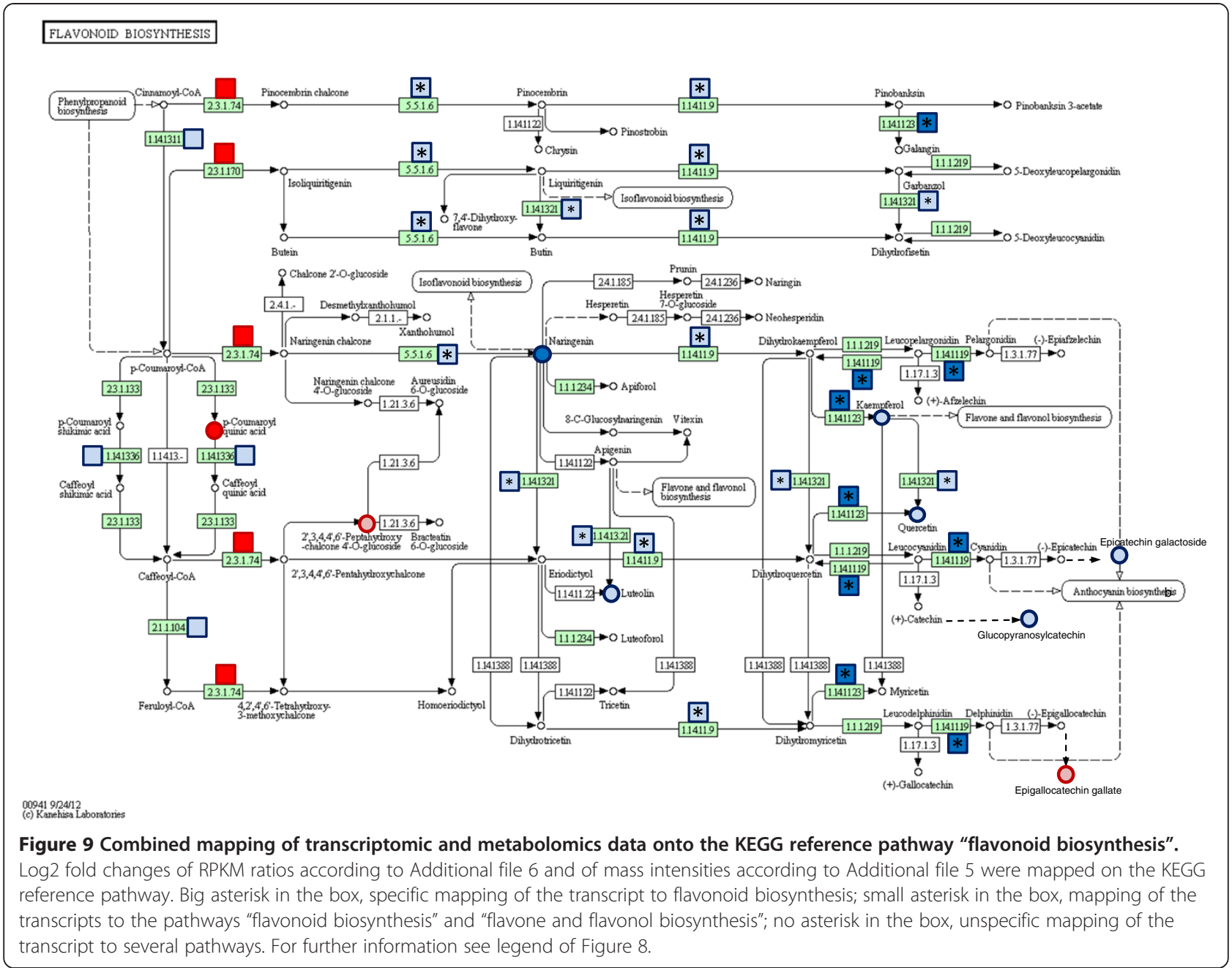

are related to differences in chromatin remodelling in $\mathrm{T}$ - and S-oaks remains an open question.

\section{Defence responses: metabolites}

Metabolically, T-oak leaves were very rich in galloyl flavonol glycosides, condensed and hydrolysable tannins, and phenolic glycosides. Conversely, leaves of the S-oak genotype had a greater abundance of flavonoid glycosides and some related intermediates, of plastidic terpenoid intermediates, and of sugars and nucleotides. The results of our analysis are in agreement with those of our earlier investigation of soluble polyphenols performed with high-performance liquid chromatography (HPLC), which showed higher constitutive concentrations of some quercetin 3-glycosides and the PA precursor catechin in T-oaks than in S-oaks [29]. Moreover, the non-targeted metabolomic analysis revealed higher levels of plastidic terpenoid intermediates in S-oaks, which could be sustained and may therefore explain the increased herbivore-induced emission rates of monoterpenes previously observed in these lines [29].

\section{Flavones and tannins}

Flavonoids, particularly condensed tannins such as PA, are biologically active compounds that play an important role in plant-insect interaction $[40,41]$. The higher levels of galloylated flavonol glucosides in T-oaks compared to S-oaks after feeding (Figure 10B) may play a role in oak resistance. Once, it was believed that tannins were "quantitative defences" limiting protein digestion by herbivorous insects [42], but now it seems that the most important role of tannins is their pro-oxidant activity [43]. The oxidation of phenolics in the guts of insects produces ROS (e.g., quinones, peroxides), which can damage both essential nutrients and midgut tissues and therefore negatively influence insect performance [44].

The concentrations of hydrolysable and condensed tannins in Quercus robur have been considered to be negatively correlated with insect abundance since the first pioneering study [45]. Many other studies in different woody plant species have demonstrated the functional role of hydrolysable and condensed tannins as plant defences against generalist insects [46]. There are 


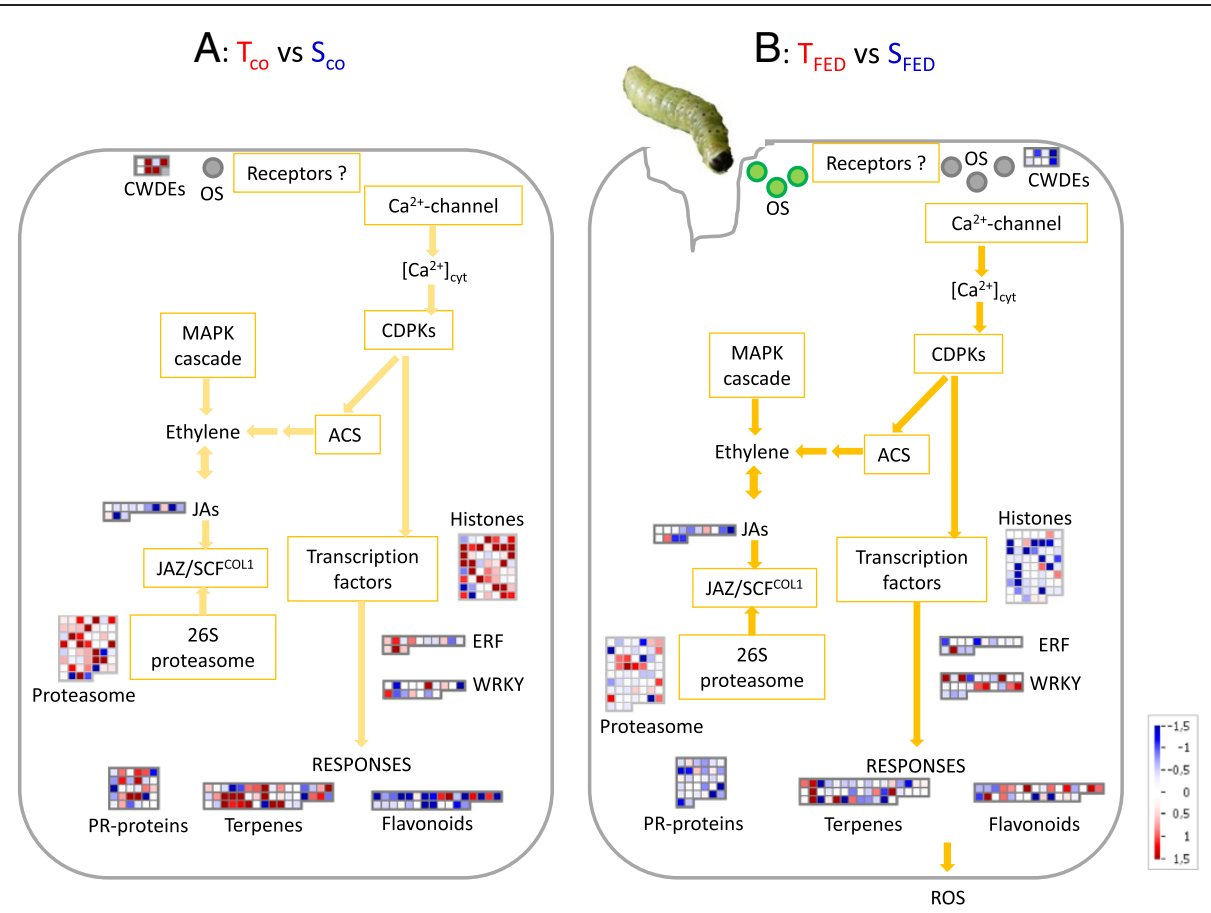

Figure 10 Model of a signalling cascade for oak's constitutive and induced defence response. The model of the cascade is derived from a model recently published by Arimura et al. [32]. A: In the unfed control, the cascade is expected to be triggered by some 'damaged-self' oligosaccharids (OS; grey circles) acting as elicitors activated by constitutively expressed cell wall degrading enzymes (CWDE; higher expressed in T-oaks than in S-oaks). B: Feeding by the leaf chewing insect T. viridana induces the release of herbivore-derived OS (green circles; elicitors) as well as of 'damaged-self' OS and therefore initiates the cascade. The cascade itself is the same for the constitutive and induced defence response with different expression of transcripts in T- and S-oaks. Red squares represent transcripts stronger expressed in T-oaks and blue squares represent transcripts with higher expression in S-oaks. Transcripts assigned to the following MapMan BINs are presented: cellulases and beta -1, 4-glucanases (CWDEs) belonging to cell wall degradation, jasmonate (JAs) related to hormone metabolism, proteasome (Proteasome) belonging to protein degradation, isoprenoids (Terpenes) and flavonoids (Flavonoids) related to secondary metabolism, ERF transcription factor family (ERF, ethylene-responsive factors), WRKY transcription factors (WRKY) belonging to regulation of transcription, histone (Histone) related to DNA synthesis/chromatin structure. Abbreviations: ACS, 1-aminocyclopropane-1-carboxylate; JAZ, jasmonate ZIM-domain; OS, oligosaccharids (elicitors); ROS, reactive oxygen species; SCF, SCF-type E3 ubiquitin ligase SCF ${ }^{\mathrm{CO}}$.

also counter-examples where generalists, such as the forest tent caterpillar, are sensitive to hydrolysable tannins, while others, such as the white-marked tussock moth (Orgyia leucostigma)[47] and the gypsy moth (Lymantria dispar)[13,43], are tannin-resistant. The same is true for condensed tannins [48]. The defensive effects of condensed tannins in Quercus sp. are even stronger on specialist insects [12]. For the autumnal moth (Epirrita autumnata), it has been shown that high gallotannin concentration reduces the growth rate of this insect, whereas PAs impair larval growth only when the gallotannin content is low [49]. A more recent study [50] concluded that ellagitannins are the most bioactive tannins, while gallotannins have intermediate to low bioactivity and condensed tannins have low oxidative activities. Although we observed clear genotypic differences in tannin patterns and galloylated flavonol glycoside levels, the biological effect of these differences on green oak leaf roller larvae seem to be rather marginal. Our previous study $[29,51]$ showed that larval mortality was equal on both oak genotypes, but larvae developing on T-oaks needed more leaf biomass to gain similar weights to larvae reared on S-oaks. Therefore, we speculate that the enrichment of gallotannins, such as corilagin, in the foliage of T-oaks may play a role in the defence properties in this resistant oak type. Furthermore, in our previous study, we found that some substances in S-oaks seem to attract female T. viridana [29]. In a recent study with a chrysomelid beetle, luteolin-7glycoside was identified as a key substance in determining the attractiveness of plants to the females [52]. The beetles preferred the plants with high amounts of luteolin-7-glycosides [52]. This finding fits very well with our observation of high levels of luteolin-7-glycosides in S-oaks.

\section{Terpenoids}

In a previous study, we showed that $T$. viridana avoided T-oaks, which may have occurred because their blend of volatile organic compounds contained a higher ratio of 
sesquiterpenes and higher emission rates of $\alpha$-farnesene and germacrene D [29]. The transcriptomic data (Figure 8) support the higher sesquiterpene activities and emission rates measured in T-oaks. We found higher expression levels (constitutive and induced) of a putative sesquiterpene synthase in T-oaks (Figure 5), which showed 75\% amino acid identity to a germacrene D synthase of Vitis vinifera (XP_003634696.1).

We observed a clear increase in the transcript levels of plastidic MEP pathway-related genes and metabolites in S-oaks after pathogen feeding (Figure 8). Because the biosynthesis of monoterpenes originates in the plastidic MEP pathway [53], the observed transcriptomic and metabolomic data agree well with the more pronounced herbivory-induced emission of monoterpenes from the susceptible oak type observed in our previous study [29]. Herbivore feeding elicits the accumulation of traumatic acid (TA), as observed clearly in damaged oak leaves. This dicarboxylic acid is a potent wound-healing agent in plants that is associated with JA biosynthesis. The volatile form of JA, methyl jasmonate, induces the activation of sesquiterpene synthases [54]. Therefore, the different emission patterns of sesquiterpene (which is emitted at higher levels in T-oaks) and the nerolidol (a sesquiterpene) derivative DMNT (which is emitted at higher levels in S-oaks) observed in T- and S-oaks [29] might be under the control of the phytohormone JA, which was synthesised at different levels in these two lines (Figure 10B). However, further studies are needed to determine whether there is a direct involvement of JA in controlling the different terpenoid profiles of the T- and S-oaks.

\section{Different defence strategies of T- and S-oaks}

The differences in the results of transcriptomic and metabolomic profiling between $\mathrm{T}$ - and S-oaks led us to the assumption that the two oak types follow different defence strategies. There are several theories about effective plant defence strategies against pathogens and herbivores. These include the Quantitative Defence Theory [55], the Optimal Defence Theory (ODT) [56,57], the Growth-Differentiation Balance (GDB) hypothesis [56,58,59], and the Resource Availability Hypothesis (RAH) [60-62]. Furthermore, there has been much general discussion of the advantages and disadvantages of constitutive and induced defence responses $[63,64]$; and references cited therein). However, the complexity of the defence response in plants often also leads to questioning of the proposed theories $[55,57,63]$. Herms and Mattson [58] got to the heart of all these theories with the title of their review "The dilemma of plants: To grow or defend". This title highlights the recurring theme in all defence theories, which is that defence is costly.

The most important advantage to possessing constitutive defence, exemplified in T-oaks by the high levels of bioactive tannins, is the fast response during herbivore attack. These plants are defended from the first moment of attack, whereas a 'just-in-time' induced defence strategy can take hours to days to protect the plant against such an attack. Furthermore, a constitutive defence can perhaps lead to a reduction in the number of attackers because, when volatile substances act as a direct defence, the insects may not even lay their eggs on the resistant plants. We suppose that this is the case for our T-oaks [29]. Our hypothesis that T-oaks follow a constitutive defence strategy is further supported by the higher levels of constitutive expression of sesquiterpenes and cell wall-degrading beta-glucanase genes.

Plants with induced resistance might have an advantage [63] if constitutive resistance against herbivores incurs fitness costs, such as reduced reproduction or lower growth rate. This advantage has been shown for the sticky monkey flower (Diplacus aurantiacus), where genotypes with higher resin concentrations had a lower growth rate [65]. Such allocation costs occur when large quantities of fitness-limiting resources are reserved for resistance traits. Quercus robur is one of the tree species that host the highest number of herbivorous insects [66]. Thus, most oaks are permanently attacked, but severe defoliation, e.g., by green oak leaf roller larvae, only occurs every five or six years and then only for one or two years in a very strong manner. It is therefore questionable whether the costs of these attacks justify a permanent resistance. The T-oak genotypes seem to follow the strategy of constitutive direct defence against the herbivores with the success to become less defoliated by the green oak leaf roller than S-oaks [29]. Interestingly, S-oaks have high constitutive transcript levels of a gene encoding the defence substance osmotin 34, which is known to function in the defence against biotic stress $[67,68]$. We do not know whether the specialist $T$. viridana is already adapted to a high level of osmotin34. However, the capability of forest insects to adapt to defence substances does exist, as demonstrated for the resistance of Lymantria dispar to tannins [13].

A commonly found trade-off between constitutive and induced defences occurs when the investment in constitutive defence is already high. In this case, fewer inducible defence responses exist $[57,69]$. This is exactly what we found for the two different oak types (Figure 1). In light of the present data, we conclude that the T-and S-oak types differ in their metabolic profiles and the levels of key metabolites and that T-oaks rather follow the strategy of constitutive defence, while S-oaks follow the 'just-in-time' strategy of induced defence (Figure 10A, B).

\section{Conclusions}

The transcriptomic and metabolomic differences identified in this study, together with our previous physiological and behavioural results, deepen our understanding of plant 
defence responses to specialist herbivore attack. Our data provide valuable information that paves the way for the identification of molecular and biochemical biomarkers. We identified several promising candidate genes in the functional groups 'protein', 'secondary metabolism', 'DNA', and 'cell'. These sequences, together with transcripts of other functional groups, will be checked for SNPs and InDels that may explain the differences in defence between the two oak types. Additionally, further tests will be performed for the development of biochemical markers. The knowledge gained from this study provides the basis for developing a method for the early selection of potentially green oak leaf roller-resistant genotypes in natural pedunculate oak populations.

\section{Methods}

\section{Plant and insect materia}

During an outbreak of Tortrix viridana L. (Lepidoptera, Tortricidae) in forest stands of North Rhine-Westphalia in 2003 to 2005, individuals of Quercus robur L. were classified as heavily defoliated and defined as susceptible ('S-oaks') or were classified as only slightly defoliated and defined as resistant ('T-oaks') using standard pictures to estimate the degree of defoliation [70]. These trees belonged to three genetically different populations (named 'Asbeck', 'Muenster' and 'Warendorf') aged between 150 and 180 years (details on the oak stands were reported previously) [71]. We selected late and early bud-bursting individuals among both resistant and susceptible oaks. Among all forest stands analysed, the selected individuals of $\mathrm{T}$ - and $\mathrm{S}$-oaks from the population 'Asbeck' showed the most obvious differences in defoliation rate. In July 2008, 100 branches from eight individuals from the two tree groups were cut out the canopy and grafted onto $Q$. robur saplings to provide manageable oak material for our experiments [28].

Hybridisation between Q. robur and Q. petraea is quite common in natural oak populations, and the hybrids are often difficult to distinguish based on morphology [72]. Therefore, the selected individuals were tested for their species purity using eight microsatellite markers located in five different linkage groups [73]. Five of the eight grafted individuals were pure Q. robur. Thus, all experiments were carried out using these five pure clones of Q. robur-grafted plants (T-oaks: ASB2a, ASB14a, ASB17a; S-oaks: ASB13b, ASB47b). More detailed information about these oak clones and the rearing of the insects has been given previously [29].

\section{Preparation of the oak material for RNA analysis}

At the end of April 2009, one $3^{\text {rd }}$ or $4^{\text {th }}$ instar larva of T. viridana was placed on each of 10 totally unfed grafted oaks per clone (the above-mentioned three T-oak clones and two S-oak clones). The experiment was performed within a phytochamber with the light switched on during the $16 \mathrm{~h}$ the experiment lasted. These 50 trees and 50 additional oaks without larvae (uninfected control plants) were covered with gauze to prevent larvae from breaking out and, for the control plants, to have the same experimental conditions. After $16 \mathrm{~h}$ of rearing, the larvae were removed and both fed and unfed leaves from treated (FED) and control plants (CO) were individually frozen in liquid nitrogen immediately after the experiment.

Because the budburst of the five clones differed slightly, the experiment was performed during a time span of 14 days, so the leaves used for the experiments were at the same developmental stage for all clones.

\section{RNA isolation}

Because of the high levels of phenolic compounds in oak leaves, which are known to hamper RNA extraction, a method based on the protocol originally published by Boom et al. [74] and modified by Hahn [75] was used. The only further modification was storage of the RNA at $-70^{\circ} \mathrm{C}$ instead of $-20^{\circ} \mathrm{C}$.

\section{RNAseq analysis}

For the T-oak fed sample, RNA was prepared from three clones with three individuals per clone. For the S-oak fed sample, RNA was prepared from two clones with three individuals each. The RNA samples were pooled for each tree sample and used for sequencing. Two separate cDNA libraries were created from $1 \mu \mathrm{g}$ RNA of each of the two samples by oligo-dT priming (GATC Biotech AG, Konstanz, Germany). Both libraries were sequenced by GATC Biotech AG (Konstanz, Germany) using an Illumina/Solexa Genome Analyser to create single-end reads of $36 \mathrm{bp}$ length (12.5 million reads for T-oaks and 12.3 million reads for S-oaks; Solexa reads available at the Short Read Archive (SRA) at EMBL-EBI [EMBL: ERP002577]). Sequencing of unfed control plants was performed using the two above mentioned T-oak clones and two of the above-mentioned S-oak clones with 1 and 2 individuals per clone, respectively. Two separate cDNA libraries were created from $1 \mu \mathrm{g}$ RNA and sequenced by GATC Biotech AG (Konstanz, Germany) using an Illumina/Solexa Genome Analyser to create single-end reads of 101 bp length (80.5 million reads for T-oaks and 124.8 million reads for S-oaks; Solexa reads available at the SRA at EMBL-EBI [EMBL: ERP002577]).

\section{Bioinformatic analyses of the RNAseq data Generation and annotation of a $Q$. robur reference set of transcript sequences}

For Q. robur, no genomic sequence is available. Therefore, a nearly non-redundant $Q$. robur reference set of transcript sequences (Q. robur reference set) was created in silico for the subsequent quantification of the sample- 
specific transcripts. The reference set consisted of 7,170 Q. robur Unigene sequences (NCBI, v1) and 7,377 additional Q. robur ESTs from Evoltree [76,77]. All corresponding reference sequences (14,547 sequences) were annotated using the MapMan ontology which is specifically tailored to plants and has been designed to be as free of redundancy as possible [30]. The sequences were assigned to MapMan BINs (functional classes/subclasses) and specific gene functions were predicted using the Mercator tool [78]. The prediction of gene function by Mercator is based on similarity to known plant sequences, especially to $A$. thaliana, and to conserved protein domains. More than $52 \%$ of the reference transcripts were annotated in MapMan (Additional file 6).

\section{Transcript quantification in the four $Q$. robur samples}

Transcripts were quantified in each of the four pooled samples by mapping the related trimmed reads to the 14,547 sequences of the Q. robur reference set using the Read Mapper (Beta v1.0 program of the CLC Genomics Workbench 5.1 suite; CLC bio, Aarhus, Denmark) with default parameters (but with 0.9 overlap and 0.95 identity). Nonspecific matches were randomly treated by default. As an expression measure, RPKM was used in an effort to normalise for the differences in the numbers of mapped reads between the different samples. Approximately 35\% of the reads from the control samples and approximately $53 \%$ of the reads from the fed samples mapped to the reference set (data not shown). The derived RPKM values of each reference gene are summarised for all four samples in Additional file 6.

Log2 fold changes for the expression values (RPKM values) from the following sample comparisons are listed in Additional file 6: T-oak control $\left(\mathrm{T}_{\mathrm{CO}}\right)$ versus S-oak control $\left(\mathrm{S}_{\mathrm{CO}}\right)$, T-oak fed $\left(\mathrm{T}_{\mathrm{FED}}\right)$ versus $\mathrm{S}$-oak fed $\left(\mathrm{S}_{\mathrm{FED}}\right)$, T-oak fed versus T-oak control $\left(\mathrm{T}_{\mathrm{IND}}\right)$, and $\mathrm{S}$-oak fed versus $\mathrm{S}$-oak control $\left(\mathrm{S}_{\mathrm{IND}}\right)$.

Only those transcripts showing any value when deriving log2 fold changes (i.e., transcripts with RPKM values different from zero) in each of the compared samples were included in the subsequent analyses to avoid incorrect results due to a missing representation of a transcript in one sample caused by variation in the library preparation or the sequencing procedure.

Transcript mapping to MapMan BINs and different MapMan pathways, and Wilcoxon Rank sum test of BINs

For each of the analysed sample comparisons, transcript identifiers and the related $\log 2$ fold ratios were imported into the MapMan desktop tool [30] (v3.5.1.; downloaded from MapMan Site of Analysis) [79]. In addition, the MapMan annotation file for the $Q$. robur reference set (see above) was imported into the tool. Thus, data were mapped to MapMan BINs, which allowed the visualisation of the data on different MapMan pathways and other biological processes.

Using the Wilcoxon rank sum test integrated in the MapMan tool, BINs were identified that showed an average BIN response that was significantly different from the response of the other BINs, as indicated by their corrected p-values in the test (Benjamini Hochberg correction; False Discovery Rate $(F D R)<5 \%, \mathrm{p}<0.05)$ [80].

\section{Selection of specific transcript groups (Groups of differentially expressed transcripts and induced transcripts)}

To compare the transcript levels of $\mathrm{T}$ - and S-oaks after feeding, all transcripts with $\log 2$ fold changes $\geq 1.5$ ( $\mathrm{T}_{\mathrm{FED}}>$ $\left.\mathrm{S}_{\mathrm{FED}}\right)$ or $\leq-1.5\left(\mathrm{~T}_{\mathrm{FED}}<\mathrm{S}_{\mathrm{FED}}\right)$ were selected as transcripts that were differentially expressed between $\mathrm{T}$ - and S-oaks after feeding (Additional file 3). All transcripts with $\log 2$ fold changes $\geq 1.5\left(\mathrm{~T}_{\mathrm{CO}}>\mathrm{S}_{\mathrm{CO}}\right)$ or $\leq-1.5\left(\mathrm{~T}_{\mathrm{CO}}<\mathrm{S}_{\mathrm{CO}}\right)$ were selected as transcripts that were differentially expressed between T- and S-oak controls (Additional file 3).

To identify transcript changes induced by $T$. viridana feeding in $\mathrm{T}$ - or S-oaks, all transcripts with $\mathrm{T}_{\mathrm{IND}}\left(\mathrm{T}_{\mathrm{IND}}=\right.$ $\left.\log _{2}\left(\mathrm{~T}_{\mathrm{FED}} / \mathrm{T}_{\mathrm{CO}}\right)\right)$ values and $\mathrm{S}_{\mathrm{IND}}$-values of $\geq 1.5$ or of $\leq-1.5$ were selected as transcripts induced by $T$. viridana feeding in both $\mathrm{T}$ - and S-oaks. Up-regulated transcripts showed $\log 2$ fold changes $\geq 1.5$, while down-regulated transcripts showed log fold changes $\leq-1.5$ (Additional file 3 ).

\section{Analysis of functional over- and under-representation}

Over- and under-representation analysis of MapMan BINs in different transcript groups was carried out using the plugin BiNGO [81] (v2.3) for the software package Cytoscape [82] (v2.6.1). A MapMan ontology file was created for BiNGO using a PERL script. The Q. robur reference set with the assigned MapMan annotation (see above) was used as a reference for the over- and underrepresentation analysis. A related Q. robur MapMan annotation file was created for BiNGO using a PERL script. Statistically significant BINs consisting of either over- or under-represented transcripts were selected according to their corrected p-value (False Discovery Rate, FDR rate $\leq 2 \%$ ) using a hypergeometric test.

\section{cDNA synthesis and semi-quantitative PCR}

For semi-quantitative PCR experiments, RNA was isolated from the five oak clones as described previously, and cDNA was synthesised by oligo-dT priming based on the SMART PCR cDNA Synthesis KIT (Clontech Laboratories, USA; Protocol No. PT3041-1).

For validation of the expression value results for candidate genes by semi-quantitative PCR, cDNAs were pooled from the same number of individuals per clone as for the RNAseq analysis. Following a standard protocol, PCR reactions contained appropriate amounts of template cDNA (2 to $10 \mathrm{ng}$ ), $50 \mathrm{mM} \mathrm{KCl,} 20 \mathrm{mM}$ Tris- 
$\mathrm{HCl}$ (pH 8.4), $1.8 \mathrm{mM} \mathrm{MgCl} 2,200 \mu \mathrm{M}$ dNTPs, 1 unit Taq polymerase, and $0.4 \mu \mathrm{M}$ of each primer (detailed primer information is given in Additional file 7) in a total volume of $25 \mu \mathrm{l}$. PCR was carried out in a Biometra Personal Thermocycler (Göttingen, Germany) with a pre-denaturation step at $94^{\circ} \mathrm{C}$ for $4 \mathrm{~min}$, followed by 25 cycles of $93^{\circ} \mathrm{C}$ for $1 \mathrm{~min}$, incubation at a suitable annealing temperature for each primer combination $\left(50^{\circ} \mathrm{C}\right.$ to $60^{\circ} \mathrm{C}$ ) for $45 \mathrm{sec}$, and $72^{\circ} \mathrm{C}$ for $1 \mathrm{~min}$, followed by a final elongation at $72^{\circ} \mathrm{C}$ for $5 \mathrm{~min}$. PCR amplification products were checked on a $1.2 \%$ agarose gel in $0.5 \mathrm{x}$ TBE buffer stained with RotiSafe (Carl Roth $\mathrm{GmbH}+$ Co. KG, Karlsruhe, Germany). SmartLadder (Eurogentec, Cologne, Germany) was used as the size standard.

PCR was conducted with (i) different cycle numbers (25, 30 and 32) and (ii) different template cDNA concentrations to validate the linearity of the measured expression values.

\section{Description of the material for the metabolomic analyses}

Metabolomic analysis was performed from the same leaf material as used for RNAseq. In addition, all leaf material collected for the physiological and behavioural experiments described in Ghirardo et al. [29] was analysed covering metabolomic changes $32 \mathrm{~h}$ after onset of insect feeding. Details of materials and methods can be found in Ghirardo et al. [29]. In brief, plants were fed by $3^{\text {rd }}$ or $4^{\text {th }}$ instars of $T$. viridana under controlled conditions inside a phytochamber $(16 / 8 \mathrm{~h}$ light/darkness). Shoots of T- and S-oaks were separately enclosed into Perspex glass cuvettes and grown for $48 \mathrm{~h}(16 \mathrm{~h}$ unfed followed by $32 \mathrm{~h}$ feeding) at $19^{\circ} \mathrm{C}$ and $50-$ $150 \mu \mathrm{mol}$ photons $\mathrm{m}^{-2} \mathrm{~s}^{-1}$ PAR (bottom-top). Harvested leaves of fed plants were separated between (i) T-oaks ("T" leaves) and S-oaks ("S" leaves), (ii) leaves, directly damaged by larvae ("D" leaves) and intact ("I" leaves; untouched leaves randomly selected - 4 leaves for each plant - of the same fed plants), (iii) plants with a leaf stage of development that naturally experience the larvae feeding; i.e. 2-4 weeks after bud break ("Y" (young) leaves) and plants start to host the oviposition process of adult female moth of $T$. viridana; i.e. 6-8 weeks after bud break ("O" (old) leaves). Individual experiments were performed with 4 different clones (T-oaks: ASB17a, ASB2a; S-oaks: ASB47b, ASB13b) and 4-5 biological replicates for each clone.

\section{Non-targeted metabolomics}

Non-targeted metabolome analysis was achieved by molecular mass assignment of high-resolution mass spectra obtained using a Fourier Transform Ion Cyclotron Resonance Mass Spectrometer (FT-ICR-MS, APEX Qe, Bruker, Bremen, Germany) equipped with a 12-Tesla superconducting magnet and an Apollo II electrospray (ESI) source.
Metabolites were extracted from $20 \mathrm{mg}$ of each sample with $500 \mu \mathrm{L} \mathrm{CH} \mathrm{CH}_{3} \mathrm{OH}: \mathrm{H}_{2} \mathrm{O}$ solution (1:1, v:v) for $15 \mathrm{~min}$ in ultrasonic bath. After centrifuging for $10 \mathrm{~min}$. at $10,000 \mathrm{rpm}, 400 \mu \mathrm{L}$ of supernatant was further diluted with $500 \mu \mathrm{L}$ of $\mathrm{CH}_{3} \mathrm{OH}: \mathrm{H}_{2} \mathrm{O}$ (75:25, v:v). Samples were kept at $4^{\circ} \mathrm{C}$ and introduced at a flow rate of $2 \mu \mathrm{L} \mathrm{min}{ }^{-1}$ into the ionization source (ESI), run in negative operation mode and therefore generating mono-charged ions. The spectra were acquired with a mass-to-charge ratio $(\mathrm{m} / \mathrm{z})$ range of 120-1,000 and a time domain of 1 Megaword. Spectra were internally calibrated using both primary and secondary metabolites; calibration errors were always below 0.05 ppm. Peak lists were obtained exporting peak mass intensities of FT-ICR ESI (-) spectra with a signal to noise $(\mathrm{S} / \mathrm{N})$ ratio of two. Peak lists of different samples were aligned into a single matrix within a precision of $>0.7 \mathrm{ppm}$.

\section{Analysis of the metabolomic data}

Data were analysed using a multivariate data analysis (MDA) approach using the software package 'The Unscrambler' (v. 8.0, CAMO A/S, Norway). First, data were analysed by PCA, using the peak list as X-variable, logarithmically transformed with $\mathrm{X}=\log 2 \mathrm{X}$. The PCA was calculated after centering the data and weighting the data with 1 s.d. $^{-1}$ (unit variance). Significant discriminant masses between T- and S-oaks (T vs. S), systemic and local responses (I vs. D), and developmentally different leaves (O vs. Y) were searched by partial least square regression (PLSR) and Martens' test [83]. In the PLSR, Y-values described either the genotype, (with $\mathrm{T}=1$ and $\mathrm{S}=0$ ), or the systemic responses (with $\mathrm{D}=1$ and $\mathrm{I}=0$ ), or the age of the leaves (with $\mathrm{O}=1$ and $\mathrm{Y}=0$ ) and the $\mathrm{X}$-values contained the matrix of mass intensities with a threshold of $6.37 \mathrm{e}^{5}$. For identification of significant discriminant masses, annotation was automatically achieved via the portal MassTRIX3 [84,85], by using KEGG/API [86]. For the annotation we used KEGG combined with Human Metabolome Database (HMDB) [87] and with expanded lipids from LipidMaps (LMPK; version 06-2011: As reference organism we selected Populus trichocarpa because species of the genus Quercus are not included so far) [88]. In addition, the structure of uncertain annotated metabolites was confirmed with ChemSpider [89]. Next, the results were filtered manually with a maximal mass error acceptance of $1.3 \mathrm{ppm}$, the error caused by spectra alignment. Finally $\log 2$ ratios of mass spectra intensities were calculated for $\mathrm{T} / \mathrm{S}, \mathrm{O} / \mathrm{Y}, \mathrm{D} / \mathrm{I}$ in order to visualise in HeatMaps up- or down- regulation of the different metabolites grouped into the main metabolic pathway according to KEGG [31].

\section{Mapping of transcriptomic and metabolomic data to KEGG pathways}

The web-based functional annotator KAAS (KEGG Automated Annotation Server) [51,90] was used to map 
the transcript identifiers to $\mathrm{KO}$ numbers thus assigning the transcripts to KEGG pathways (single bidirectional best hit-method using the representative set for genes at KAAS; default blast score of 60). All metabolites were included in the pathway mapping, which showed statistically significant discriminant masses between $\mathrm{T}$ - vs. S-oaks after feeding (see above). The selected masses were mapped to specific metabolites in KEGG pathway displays using MassTRIX3 [84,85]. Log2 fold ratios of mapped transcripts and metabolites were displayed onto the KEGG pathways in color code.

\section{Additional files}

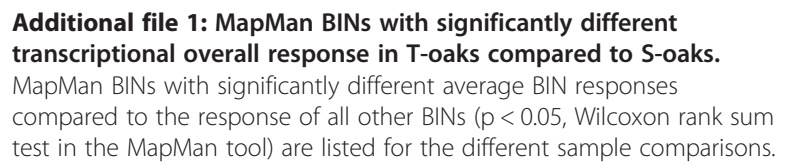

Additional file 2: Most significant MapMan BINs with different transcriptional overall response in T-oaks compared to S-oaks. MapMan BINs with most significantly different average BIN responses compared to the response of all other BINs ( $p<0.025$, Wilcoxon rank sum test in the MapMan tool; Additional file 6) are presented for the different sample comparisons.

Additional file 3: Candidate gene groups with related raw data of transcript quantification. Functional annotation (MapMan), transcript counts and RPKM values in the different samples as well as derived log fold changes of RPKM values (for the indicated sample comparisons) are summarized for different candidate gene groups. "T and S_ind_up", $T_{\mathbb{N D}}>=1.5$ and $S_{\mathbb{N D}}>=$ 1.5); "T and S_ind_down", $T_{\mathbb{N D}} \leq-1.5$ and $\left.S_{\mathbb{N D}} \leq-1.5\right)$. $T_{\mathrm{FED}}>\mathrm{S}_{\mathrm{FED}} / T_{\mathrm{CO}}>\mathrm{S}_{\mathrm{CO}}, \log 2$ fold changes $\geq 1.5 ; T_{\text {FED }}<\mathrm{S}_{\mathrm{FED}} / T_{\mathrm{CO}}<\mathrm{S}_{\mathrm{CO}}$ log 2 fold changes $\leq-1.5$.

Additional file 4: Nucleotide sequences of the transcripts listed in Tables 1, 2, and 3. All nucleotide sequences assigned to the transcripts identifiers which are listed in Tables 1, 2, and 3 are provided.

Additional file 5: Complete list of annotated masses for metabolomic identification. Compounds are sorted according to which KEGG [31] group the compound belongs (alphabetically ordered) and then by values of $\log 2 \mathrm{~T} / \mathrm{S}$ ratios (increasing). All log ratios displayed are significant (Martens' test [83]; otherwise value set to 0 ). In bold are highlighted the compounds reported in results section. Columns: (A) compound number; (B) exact annotated mass; (C) the error in ppm; (D), the ID of KEGG/HMDB/LMGP/ChemSpider databases $[31,88,89]$; (E), the molecular formula (obtained from KEGG) [31]; (F) the proposed identification with possible isomers, (G) the additional (marked with " $x$ ") identification of the corresponding $\mathrm{C}^{13}$ and $(\mathrm{H}) \mathrm{O}^{18}$ isotopes; (I) category of which averages (AV) and standard error (S.E.) of MS intensities refer to; $(J)$ the averages and (K) S.E. of MS intensities of resistant $(T ; n=26)$ or old $(O ; n=16)$ or damaged $(D ; n=26)$ leaves and $(L)$ averages and $(M)$ S.E. of MS intensities of susceptible $(S ; n=26)$ or young $(Y ; n=38)$ or intact $(\mathrm{I} ; \mathrm{n}=28)$ leaves; (N) log2 ratios of $\mathrm{T} / \mathrm{S},(\mathrm{O}) \log 2$ ratios of $\mathrm{O} / \mathrm{Y} ;(\mathrm{P}) \log 2$ ratios of $\mathrm{D} / \mathrm{l} ;(\mathrm{Q})$ main KEGG compound group, $(\mathrm{R}-\mathrm{U})$ alternative pathways for isomers or compounds belonging to more groups.

Additional file 6: Raw data of transcript quantification for all transcripts of the reference set in the analysed samples. Functional annotation (MapMan), transcript counts and RPKM values in the different samples as well as derived log fold changes of RPKM values (for the indicated sample comparisons) are summarised for all transcripts (Identifiers) of the reference transcript set used for mapping the Solexa reads.

Additional file 7: Detailed information of primers used for validation of the candidate genes. The associated gene, names of primers, primer sequences and the used annealing temperature are given. Within the primer names $F$ means the forward and $\mathrm{R}$ means the reverse primer.

\section{Abbreviations}

BINs: MapMan functional categories; CDPK: Calcium-dependent kinases; DMNT: Homoterpene 4,8-dimethylnona-1,3,7-triene; FA: Fatty acids; FT-ICRMS: Fourier Transform Ion Cyclotron Resonance Mass Spectrometer;

GDB: Growth-Differentiation Balance hypothesis; HIPVs: Herbivory-induced plant volatiles; HPLC: High-performance liquid chromatography; JA: Jasmonic acid; MDA: Multivariate data analysis; MAPK: Mitogen-activated protein kinase; MEP pathway: 2C-methyl-D-erythritol 4-phosphate pathway; ODT: Optimal Defence Theory; PA: Proanthocyanidins; PCA: Principal components analysis; PLSR: Partial least squares regression; RAH: Resource Availability Hypothesis; RNA-seq: RNA sequencing; ROS: Reactive oxygen species; RPKM-value: Reads per kilobase of exon model per Million mapped reads; S-oak: Susceptible oak type; TA: Traumatic acid; T-oak: Resistant oak type.

\section{Competing interests}

The authors declare that they have no competing interests.

\section{Authors' contributions}

BK performed the bioinformatic analysis, the combined mapping of transcriptomic and metabolomic data, and drafted the manuscript. AG contributed to the experimental design, processed the metabolomic data, performed MDA analysis and participated in drafting the manuscript. JPS participated in conceiving of the study, its design and coordination, contributed to the metabolomic analysis, and participated in drafting of the manuscript. BaK and PSK contributed by running the non-targeted metabolome analysis. MF participated in conceiving of the study, its design and coordination, and participated in drafting of the manuscript. HS conceived of the study, designed and coordinated it, performed and analysed gene expression data and drafted the manuscript. All authors read and approved the final manuscript.

\section{Acknowledgements}

This project is financially supported by the 'Deutsche Forschungsgemeinschaft' (DFG, no. FL 263/19-1), Bonn, Germany [91]. We thank our technical assistants Susanne Jelkmann (vTI) and Ina Zimmer (EUS) for their excellent laboratory work and we like to give special thanks to our students Stefanie Thomsen and Franziska Orgel for care and breeding of the insects. Doreen Pahlke (GabiPD [92] team) is acknowledged for submitting sequence data to EMBL-EBI.

\section{Author details}

'Thünen Institute of Forest Genetics, Sieker Landstrasse 2, D-22927, Grosshansdorf, Germany. ${ }^{2} \mathrm{Helmholtz} Z$ Zentrum München, Institute of Biochemical Plant Pathology, Research Unit Environmental Simulation, Ingolstädter Landstr. 1, D-85764, Neuherberg, Germany. ${ }^{3}$ Helmholtz Zentrum München, Research Unit Biogeochemistry and Analytics, Ingolstädter Landstr. 1, D-85764, Neuherberg, Germany.

Received: 25 June 2013 Accepted: 17 October 2013

Published: 28 October 2013

\section{References}

1. Dixon RA: Natural products and plant disease resistance. Nature 2001, 411:843-847.

2. Saito K, Matsuda F: Metabolomics for functional genomics, systems biology, and biotechnology. Annu Rev Plant Biol 2010, 61:463-489.

3. Hartmann T: From waste products to ecochemicals: fifty years research of plant secondary metabolism. Phytochemistry 2007, 68:2831-2846.

4. Obata T, Fernie AR: The use of metabolomics to dissect plant responses to abiotic stresses. Cell Mol Life Sci 2012, 69:3225-3243.

5. Carmona D, Lajeunesse MJ, Johnson MTJ: Plant traits that predict resistance to herbivores. Funct Ecol 2011, 25:358-367.

6. Kaplan I, Halitschke R, Kessler A, Sardanelli S, Denno RF: Constitutive and induced defenses to herbivory in above- and belowground plant tissues. Ecology 2008, 89:392-406.

7. Walling LL: The Myriad Plant Responses to Herbivores. J Plant Growth Regul 2000, 19:195-216.

8. Verne S, Jaquish B, White R, Ritland C, Ritland K: Global transcriptome analysis of constitutive resistance to the white pine weevil in spruce. Genome Biol Evol 2011, 3:851-867. 
9. Tanner GJ, Francki KT, Abrahams S, Watson JM, Larkin PJ, Ashton AR: Proanthocyanidin biosynthesis in plants. Purification of legume leucoanthocyanidin reductase and molecular cloning of its CDNA. J Biol Chem 2003, 278:31647-31656.

10. Peters DJ, Constabel CP: Molecular analysis of herbivore-induced condensed tannin synthesis: cloning and expression of dihydroflavonol reductase from trembling aspen (Populus tremuloides). Plant J 2002, 32:701-712.

11. Yuan L, Wang L, Han Z, Jiang Y, Zhao L, Liu H, Yang L, Luo K: Molecular cloning and characterization of PtrLAR3, a gene encoding leucoanthocyanidin reductase from Populus trichocarpa, and its constitutive expression enhances fungal resistance in transgenic plants. J Exp Bot 2012, 63:2513-2524.

12. Forkner RE, Marquis RJ, Lill JT: Feeny revisited: condensed tannins as anti-herbivore defences in leaf-chewing herbivore communities of Quercus. Ecol Entomol 2004, 29:174-187.

13. Foss LK, Rieske LK: Species-specific differences in oak foliage affect preference and performance of gypsy moth caterpillars. Entomol Exp Appl 2003, 108:87-93.

14. Salminen JP, Karonen M: Chemical ecology of tannins and other phenolics: we need a change in approach. Funct Ecol 2011, 25:325-338.

15. Boland W, Hopke J, Donath J: Jasmonsäure- und Coronatin-induzierte Duftproduktion von Pflanzen. Angewandte Chemie 1995, 107:1715-1717.

16. Thaler JS: Jasmonate-inducible plant defences cause increased parasitism of herbivores. Nature 1999, 399:686-688.

17. Korth KL: Profiling the response of plants to herbivorous insects. Genome Biol 2003, 4:221.

18. Reymond P: DNA microarrays and plant defence. Plant Physiol Biochem 2001, 39:313-321.

19. Reymond P, Bodenhausen N, Van Poecke RM, Krishnamurthy V, Dicke M, Farmer EE: A conserved transcript pattern in response to a specialist and a generalist herbivore. Plant Cell 2004, 16:3132-3147.

20. Bräutigam A, Gowik U: What can next generation sequencing do for you? Next generation sequencing as a valuable tool in plant research. Plant Biol (Stuttg) 2010, 12:831-841.

21. Nagalakshmi U, Waern K, Snyder M: RNA-Seq: a method for comprehensive transcriptome analysis. Curr Protoc Mol Biol 2010, Chapter 4:Unit 411 11-13.

22. Gyetvai G, Sonderkaer M, Gobel U, Basekow R, Ballvora A, Imhoff M, Kersten B, Nielsen $\mathrm{KL}$, Gebhardt C: The transcriptome of compatible and incompatible interactions of potato (Solanum tuberosum) with Phytophthora infestans revealed by DeepSAGE analysis. PLoS One 2012, 7:e31526.

23. Gilardoni PA, Schuck S, Jungling R, Rotter B, Baldwin IT, Bonaventure G SuperSAGE analysis of the Nicotiana attenuata transcriptome after fatty acid-amino acid elicitation (FAC): identification of early mediators of insect responses. BMC Plant Biol 2010, 10:66.

24. Fiehn O: Metabolomics-the link between genotypes and phenotypes. Plant Mol Biol 2002, 48:155-171.

25. Aharoni A, de Vos CH R, Verhoeven HA, Maliepaard CA, Kruppa G, Bino R, Goodenowe DB: Nontargeted metabolome analysis by use of Fourier Transform Ion Cyclotron Mass Spectrometry. OMICS 2002, 6:217-234.

26. Hunter MD: Differential Susceptibility to Variable Plant Phenology and Its Role in Competition between 2 Insect Herbivores on Oak. Ecol Entomol 1990, 15:401-408.

27. Du Merle P: Egg development and diapause: ecophysiological and genetic basis of phenological polymorphism and adaptation to varied hosts in the green oak tortrix, Tortrix viridana L. (Lepidoptera: Tortricidae). J Insect Physiol 1999, 45:599-611.

28. Schröder H: Sommerveredelung bei Eichen - eine Erfolgsgeschichte. AFZ-Der Wald 2010, 5:16-17.

29. Ghirardo A, Heller W, Fladung M, Schnitzler JP, Schroeder H: Function of defensive volatiles in pedunculate oak (Quercus robur) is tricked by the moth Tortrix viridana. Plant Cell Environ 2012, 35(12):2192-2207.

30. Usadel B, Nagel A, Thimm O, Redestig H, Blaesing OE, Palacios-Rojas N, Selbig J, Hannemann J, Piques MC, Steinhauser D, et al: Extension of the visualization tool MapMan to allow statistical analysis of arrays, display of corresponding genes, and comparison with known responses. Plant Physiol 2005, 138:1195-1204.

31. KEGG PATHWAY Database. http://www.genome.jp/kegg/pathway.html.

32. Arimura G, Ozawa R, Maffei ME: Recent advances in plant early signaling in response to herbivory. Int J Mol Sci 2011, 12:3723-3739.
33. Heil M: Damaged-self recognition in plant herbivore defence. Trends Plant Sci 2009, 14:356-363.

34. Hematy K, Cherk C, Somerville S: Host-pathogen warfare at the plant cell wall. Curr Opin Plant Biol 2009, 12:406-413.

35. Misas-Villamil JC, van der Hoorn RAL: Enzyme-inhibitor interactions at the plant-pathogen interface. Curr Opin Plant Biol 2008, 11:380-388

36. Aziz A, Gauthier A, Bezier A, Poinssot B, Joubert JM, Pugin A, Heyraud A Baillieul F: Elicitor and resistance-inducing activities of beta-1,4 cellodextrins in grapevine, comparison with beta-1,3 glucans and alpha1,4 oligogalacturonides. J Exp Bot 2007, 58:1463-1472.

37. Ferrari S, Galletti R, Pontiggia D, Manfredini C, Lionetti V, Bellincampi D, Cervone F, De Lorenzo G: Transgenic expression of a fungal endopolygalacturonase increases plant resistance to pathogens and reduces auxin sensitivity. Plant Physiol 2008, 146:669-681.

38. Maffei ME, Mithofer A, Boland W: Insects feeding on plants: Rapid signals and responses preceding the induction of phytochemical release. Phytochemistry 2007, 68:2946-2959.

39. Berr A, Menard R, Heitz T, Shen WH: Chromatin modification and remodelling: a regulatory landscape for the control of Arabidopsis defence responses upon pathogen attack. Cell Microbiol 2012, 14:829-839.

40. Simmonds MSJ: Flavonoid-insect interactions: recent advances in our knowledge. Phytochemistry 2003, 64:21-30.

41. Treutter D: Significance of flavonoids in plant resistance: a review. Environ Chem Lett 2006, 4:147-157.

42. Feeny PP: Plant apparency and chemical defense. In Recent Advances in Phytochemistry. Edited by Wallace JW, Mansell RL. New York: Plenum Press; 1976:1-40.

43. Barbehenn RV, Jaros A, Lee G, Mozola C, Weir Q, Salminen JP: Hydrolyzable tannins as "quantitative defenses": Limited impact against Lymantria dispar caterpillars on hybrid poplar. J Insect Physiol 2009, 55:297-304

44. Barbehenn R, Cheek S, Gasperut A, Lister E, Maben R: Phenolic compounds in red oak and sugar maple leaves have prooxidant activities in the midgut fluids of Malacosoma disstria and Orgyia leucostigma caterpillars. J Chem Ecol 2005, 31:969-988.

45. Feeny P: Seasonal Changes in Oak Leaf Tannins and Nutrients as a Cause of Spring Feeding by Winter Moth Caterpillars. Ecology 1970, 51:565.

46. Rossiter M, Schultz JC, Baldwin IT: Relationships among Defoliation, Red Oak Phenolics, and Gypsy-Moth Growth and Reproduction. Ecology 1988, 69:267-277.

47. Karowe DN: Differential Effect of Tannic-Acid on 2 Tree-Feeding Lepidoptera - Implications for Theories of Plant Anti-Herbivore Chemistry. Oecologia 1989, 80:507-512.

48. Kopper BJ, Jakobi VN, Osier TL, Lindroth RL: Effects of paper birch condensed tannin on whitemarked tussock moth (Lepidoptera: Lymantriidae) performance. Environ Entomol 2002, 31:10-14.

49. Kause A, Ossipov V, Haukioja E, Lempa K, Hanhimaki S, Ossipova S: Multiplicity of biochemical factors determining quality of growing birch leaves. Oecologia 1999, 120:102-112.

50. Barbehenn RV, Jones $C P$, Hagerman $A E$, Karonen M, Salminen JP: Ellagitannins have greater oxidative activities than condensed tannins and galloyl glucoses at high $\mathrm{pH}$ : Potential impact on caterpillars. J Chem Ecol 2006, 32:2253-2267.

51. Moriya $Y$, Itoh M, Okuda S, Yoshizawa AC, Kanehisa M: KAAS: an automatic genome annotation and pathway reconstruction server. Nucleic Acids Res 2007, 35:W182-W185.

52. Wennström A, Hjulstrom LN, Hjalten J, Julkunen-Tiitto R: Mother really knows best: host choice of adult phytophagous insect females reflects a within-host variation in suitability as larval food. Chemoecology 2010, 20:35-42.

53. Laule O, Furholz A, Chang HS, Zhu T, Wang X, Heifetz PB, Gruissem W, Lange M: Crosstalk between cytosolic and plastidial pathways of isoprenoid biosynthesis in Arabidopsis thaliana. Proc Natl Acad Sci USA 2003, 100:6866-6871.

54. Cheng $A X$, Xiang CY, Li JX, Yang CQ, Hu WL, Wang LJ, Lou YG, Chen XY: The rice (E)-beta-caryophyllene synthase (OsTPS3) accounts for the major inducible volatile sesquiterpenes. Phytochemistry 2007, 68:1632-1641

55. Faeth SH: Quantitative Defense Theory and Patterns of Feeding by Oak Insects. Oecologia 1985, 68:34-40 
56. Barto EK, Cipollini D: Testing the optimal defense theory and the growth-differentiation balance hypothesis in Arabidopsis thaliana. Oecologia 2005, 146:169-178.

57. Moreira X, Zas R, Sampedro L: Differential Allocation of Constitutive and Induced Chemical Defenses in Pine Tree Juveniles: A Test of the Optimal Defense Theory. Plos One 2012, 7:e34006.

58. Herms DA, Mattson WJ: The Dilemma of Plants - to Grow or Defend. Q Rev Biol 1992, 67:283-335.

59. Stamp N: Can the growth-differentiation balance hypothesis be tested rigorously? Oikos 2004, 107:439-448.

60. Bryant JP, Chapin FS, Klein DR: Carbon Nutrient Balance of Boreal Plants in Relation to Vertebrate Herbivory. Oikos 1983, 40:357-368.

61. Coley PD, Bryant JP, Chapin FS: Resource Availability and Plant Antiherbivore Defense. Science 1985, 230:895-899.

62. Endara MJ, Coley PD: The resource availability hypothesis revisited: a meta-analysis. Funct Ecol 2011, 25:389-398.

63. Heil M, Baldwin IT: Fitness costs of induced resistance: emerging experimental support for a slippery concept. Trends Plant Sci 2002 7:61-67.

64. Strauss SY, Rudgers JA, Lau JA, Irwin RE: Direct and ecological costs of resistance to herbivory. Trends Ecol Evol 2002, 17:278-285.

65. Han KP, Lincoln DE: The Evolution of Carbon Allocation to Plant Secondary Metabolites - a Genetic-Analysis of Cost in Diplacus-Aurantiacus. Evolution 1994, 48:1550-1563.

66. Yela JL, Lawton JH: Insect herbivore loads on native and introduced plants: a preliminary study. Entomologia Experimentalis Et Applicata 1997, 85:275-279.

67. Lawrence CB, Singh NP, Qiu JS, Gardner RG, Tuzun S: Constitutive hydrolytic enzymes are associated with polygenic resistance of tomato to Alternaria solani and may function as an elicitor release mechanism. Physiol Molr Plant Pathol 2000, 57:211-220.

68. Petre B, Major I, Rouhier N, Duplessis S: Genome-wide analysis of eukaryote thaumatin-like proteins (TLPS) with an emphasis on poplar. BMC Plant Biol 2011, 11:33.

69. Kempel A, Schaedler M, Chrobock T, Fischer M, van Kleunen M: Tradeoffs associated with constitutive and induced plant resistance against herbivory. Proc Natl Acad Sci USA 2011, 108:5685-5689.

70. Evers J, Franz C, Körver F, Ziegler C: Waldbäume - Bilderserien zur Einschätzung von Kronenverlichtungen bei Waldbäumen. Kassel, Germany: Faste Michael Verlag; 1997.

71. Schroeder H, Degen B: Genetic structure of the green oak leaf roller (Tortrix viridana L.) and one of its hosts, Quercus robur L. For Ecol Manage 2008, 256:1270-1279.

72. Curtu AL, Gailing O, Finkeldey R: Patterns of contemporary hybridization inferred from paternity analysis in a four-oak-species forest. BMC Evol Biol 2009, 9:284

73. Scotti-Saintagne C, Mariette S, Porth I, Goicoechea PG, Barreneche T, Bodenes C, Burg K, Kremer A: Genome scanning for interspecific differentiation between two closely related oak species [Quercus robur L. and Q. petraea (Matt.) Liebl.]. Genetics 2004, 168:1615-1626.

74. Boom R, Sol CJ, Salimans MM, Jansen CL, Wertheim-van Dillen PM, van der Noordaa J: Rapid and simple method for purification of nucleic acids. J Clin Microbiol 1990, 28:495-503.

75. Hahn S: Virologische Untersuchungen an Stieleichen (Quercus robur L.) zum verursachenden Pathogen der pfropfübertragbaren chlorotischen Ringflecken. Dissertation. Humbold-Universität; 2005

76. Ueno S, Le Provost G, Leger V, Klopp C, Noirot C, Frigerio JM, Salin F, Salse J, Abrouk M, Murat F, et al: Bioinformatic analysis of ESTs collected by Sanger and pyrosequencing methods for a keystone forest tree species: oak. BMC Genomics 2010, 11:650.

77. Faivre Rampant P, Lesur I, Boussardon C, Bitton F, Martin-Magniette ML, Bodenes C, Le Provost G, Berges H, Fluch S, Kremer A, Plomion C: Analysis of BAC end sequences in oak, a keystone forest tree species, providing insight into the composition of its genome. $B M C$ Genomics 2011, 12:292.

78. Mercator pipeline for automated sequence annotation. http://mapman gabipd.org/web/guest/app/mercator.

79. MapMan Site of Analysis. http://mapman.gabipd.org.

80. Benjamini Y, Hochberg Y: Controlling the False Discovery Rate - a Practical and Powerful Approach to Multiple Testing. J R Stat Soc B Methodol 1995, 57:289-300.
81. Maere S, Heymans K, Kuiper M: BiNGO: a Cytoscape plugin to assess overrepresentation of gene ontology categories in biological networks. Bioinformatics 2005, 21:3448-3449.

82. Shannon P, Markiel A, Ozier O, Baliga NS, Wang JT, Ramage D, Amin N, Schwikowski B, Ideker T: Cytoscape: a software environment for integrated models of biomolecular interaction networks. Genome Res 2003, 13:2498-2504.

83. Martens $\mathrm{H}$, Martens M: Modified jack-knife estimation of parameter uncertainty in bilinear modelling by partial least squares regression (PLSR). Food Qual Prefer 2000, 11:5-16.

84. MassTRIX: Mass TRanslator into Pathways. http://masstrix3.helmholtzmuenchen.de/masstrix3/

85. Wagele B, Witting M, Schmitt-Kopplin P, Suhre K: MassTRIX reloaded: combined analysis and visualization of transcriptome and metabolome data. PLoS One 2012, 7:e39860.

86. KEGG API. http://www.kegg.jp/kegg/rest/.

87. Human Metabolome Database. http://www.hmdb.ca/.

88. LIPID MAPS. http://www.lipidmaps.org/.

89. ChemSpider. http://www.chemspider.com.

90. KAAS - KEGG Automatic Annotation Server. http://www.genome.jp/tools/ kaas/.

91. DFG Deutsche Forschungsgemeinschaft. http://www.dfg.de/en/.

92. GabiPD - GABI Primary Database. http://www.gabipd.org.

doi:10.1186/1471-2164-14-737

Cite this article as: Kersten et al:: Integrated transcriptomics and metabolomics decipher differences in the resistance of pedunculate oak to the herbivore Tortrix viridana L. BMC Genomics 2013 14:737.

\section{Submit your next manuscript to BioMed Central and take full advantage of:}

- Convenient online submission

- Thorough peer review

- No space constraints or color figure charges

- Immediate publication on acceptance

- Inclusion in PubMed, CAS, Scopus and Google Scholar

- Research which is freely available for redistribution
C Biomed Central 